\title{
Sustainable Synthesis of Microwave Assisted IONPs by Using Spinacia Oleracea. Enhances Resistance Against Fungal Wilt Infection by Inducing ROS and Modulating Defense System in Tomato Plants
}

Hina Ashraf ( $\square$ hina_ashraf1@hotmail.com )

University of the Punjab Quaid-i-Azam Campus: University of the Punjab https://orcid.org/0000-00034608-330X

\section{Tehmina Anjum}

University of the Punjab Quaid-i-Azam Campus: University of the Punjab

\section{Saira Riaz}

University of the Punjab Quaid-i-Azam Campus: University of the Punjab

\section{Tanzeela Batool}

University of the Punjab Quaid-i-Azam Campus: University of the Punjab

\section{Shahzad Naseem}

University of the Punjab Quaid-i-Azam Campus: University of the Punjab

\section{Iffan S. Ahmad}

University of Illinois at Urbana-Champaign

\section{Research Article}

Keywords: Tomato, fusarium wilt, IONPs, microwave (MW), green synthesis, antioxidant enzymes, ROS, greenhouse

Posted Date: August 10th, 2021

DOI: https://doi.org/10.21203/rs.3.rs-783540/v1

License: (c) (1) This work is licensed under a Creative Commons Attribution 4.0 International License. Read Full License 


\section{Abstract}

Background: Changing climate enhances the survival of pests and pathogens which eventually affects the crop yield and reduces its economic value. To attain the sustainable food security, novel approaches should be employed. Nanobased agri-chemicals provide a distinctive mechanism to increase productivity and manage phytopathogens with minimum environmental distress. In-vitro and greenhouse studies were conducted to evaluate the potential of green synthesized iron oxide nanoparticles (IONPs) in suppressing the wilt infection caused by Fusarium oxysporum f.sp. lycospersici and to improve tomato growth (Solanum lycopersicum) and fruit quality.

Results: Various microwave powers (100 W- $1000 \mathrm{~W}$ ) were used to modulate the properties of green synthesize IONPs by using spinach as a starting material. The IONPs stabilized with black coffee extract were substantively characterized by X-ray diffraction analysis, fourier transform infrared spectroscopy, dielectric and impedance spectroscopy, $\mathrm{X}$-ray photoelectron spectroscopy, Scanning and transmission electron microscopy and magnetization-analysis. XRD revealed cubic magnetite $\left(\mathrm{Fe}_{3} \mathrm{O}_{4}\right)$ phase with superparamagnetic nature, detected at all microwave powers. Binding energies of Fe 2p3/2 (712.05 eV) and $\mathrm{Fe} 2 \mathrm{p} 1 / 2(723.9 \mathrm{eV})$ of $\mathrm{Fe}_{3} \mathrm{O}_{4} \mathrm{NPs}$ was confirmed by XPS analysis observed at microwave power of $1000 \mathrm{~W}$. Uniform, spherical shaped particles with an average diameter of $4 \mathrm{~nm}$ were confirmed by SEM and TEM analysis. Significant reduction in mycelial growth and spore germination was perceived after exposure to different treatments of IONPs. Malformed mycelium, DNA fragmentation, alternation in cell membrane and ROS production in F. oxysporum indicates antimicrobial affinity of iron oxide NPs. The particles were applied both through root (before transplantation) and foliar application (after two weeks) to infected seedlings. The IONPs significantly reduced the disease severity by an average of $47.8 \%$ resulting in increased plant growth variables at exposure to $10 \mu \mathrm{g} / \mathrm{mL}$ of IONPs. Analysis of photosynthetic pigment, phenolic compounds and antioxidant enzymes in root and shoots signifies an increasing trend after exposure to various concentrations of IONPs. Correspondingly, lycopene, vitamin C, total flavonoids and protein content was substantially improved in tomato fruits after treatment of IONPs.

Conclusion: These findings of current investigation suggests that IONPs owned antifungal properties to subdue Fusarium wilt disease by boosting plant growth and fruit quality.

\section{Background}

In recent times innovative and advance technological approaches has been employed in agriculture sector to encounter the surging challenges of food-security and sustainable-production [1]. Stratagems based on "nanoparticle-technology" have releveled fascinating outputs due to their innate characteristics [2]. Novel practices in agriculture are dynamic factor of research to meet the needs for consistent food supply in exploding global population [3]. Nanotechnology, an emitting interdisciplinary field of modern era, has imperative impact on people's lives by resolving most of the scientific problems and has proven its essentiality almost in every field including agriculture and allied industries [4]. Nanoscale materials due to their distinctive properties such as improved efficacy, lesser eco-toxicity and reduced-inputs 
provides auspicious alternative for crop protection that has numerous advantages over traditional approaches and products [5]. Among various classes of nanoparticles, metal-oxide nanomaterials are generally pondered as innocuous both for environment and humans, specifically iron oxide nanoparticle (IONPs), are the most prominent and biocompatible, possess antimicrobial properties against pathogenic fungi and bacteria [6]. Now-a-days nanotechnology has a new function in agriculture by implicating suppression of pathogen infection (bacterial, viral, fungal) by improving plant nutrition and thus directly enhances nutritional value and crop yield [7]. Additionally, nanomaterials may affect plant cells and its developmental stages including seed-germination, root induction, cell-metabolism, growth-index and biomass plus alters redox level [8]. Iron is a pivotal micronutrient cognate with various physiological functions in plants but generally found as insoluble $\mathrm{Fe}^{+3}$ form, owing to low solubility of minerals having iron, one method to overcome iron-deficiency is the usage of nanoparticles either as iron or iron oxide NPs [9]. Iron oxide nanoparticles being reduced in size and having higher solubility than other complex molecules facilities plants with greater level of iron [10]. Therefore, these compounds provide optimum environment for plant enhancement and averting stress conditions by generating secondary metabolites [11]. Iron being key constituent of cell-redox reaction, behaves like a co-factor for various anti-oxidant enzymes such as catalase (CAT), superoxide-dismutase (SOD), and peroxidase (POD), acts as a scavenger of ROS [12]. Even though oxidative stress is induced in response to nanoparticles, triggers the defence mechanism in plants such as higher activities of antioxidant enzymes eventually scavenge for ROS [13]. Earlier reports indicated that during stress conditions, iron oxide nanoparticles elevated the antioxidant activity in various plants such as, Mentha piperita, [9] Triticum aestivum, $[14,15]$ Solanum lycopersicum [10] and Dracocephalum moldavica [4].

Tomato (Solanum lycopersicum L.) being the most notable crop after potato from commercial and economic perspective, ranked sixth in world by Food and Agriculture organization in terms of total annual production [16]. Crop yield is potentially reduced to $20 \%$ by soil-borne diseases that is tough to cope, alone fungal pathogens are responsible for loss of millions per years by reducing economic return [17]. Fusarium-wilt, one of the most devastating fungal-diseases, diminishing the yield index and nutritive value of various crops, particularly in tomatoes, it is initiated by Fusarium oxysporum f.sp lycopersici, affected tomato growth equally under greenhouse and field trials [18]. Although there are different traditional ways to overcome this disease such as use of resistant verities and application of fungicides, but these approaches are environmentally un-sustainable and cost ineffectual,[17] so there is a demand of time to find more innovative and effective ways to cope with fungal pathogens. Although limited number of reports available on the role of iron oxide nanoparticles in diseases management. Alam et al. reported antifungal efficacy of green synthesized iron oxide nanoparticles against polyphagous pathogen Verticillium dahlia by preventing the proliferation of mycelium [19]. $\mathrm{Fe}_{3} \mathrm{O}_{4}$ nanoparticles induces the expression of miR159c in yellow medick plant against powdery mildew [20]. In-vitro application of IONPs showed significant antifungal properties, inhibiting the spore germination in various phytopathogens such as, Aspergillus niger and Fusarium solani;[21] Rhizopus oryzae,[22] Trichothecium roseum, Cladosporium herbarum, Penicillium chrysogenum, Alternaria alternata and A. niger, [23] P. expansum, A. niger, A.alternata, P. chrysogenum, Mucor plumbeus, T. roseum and Rhizoctonia solani [24]. Earlier studies 
indicate the formation and accumulation of reactive-oxygen-species (ROS) in microbial cells impedes the multiplication ability of the pathogens depicts the underlying mechanism of metal nanoparticles, however it is commonly anticipated that antimicrobial activity relies on direct-interaction among nanoparticles and living cells [25]. magnesium oxide nanoparticles reveal antagonist activity against fungal species by acting directly on fungal cells [26]. Chitosan-coated IONPs showed significant antimicrobial activity against Escherichia coli and Bacillus subtilis by up-regulating the ROS level [27].

Tomatoes are an important part of human diet as they contain various bio-active compounds like totalphenols, lycopene, vitamin-C, carotenoids and total-flavonoids, that acts as antioxidant compounds with specific physio-chemical and biological properties, plays a beneficial role in human health [28]. As iron oxide nanoparticles are safe to be used for medical and food applications, permitted by food and drug administration (FDA) [29], making IONPs as a potential candidate to study their fungicidal activity and nutritional effects on plants.

In current investigation, it was hypothesized that green synthesized IONPs will be more efficient in suppressing fusarium wilt disease in infected tomato plants. We demonstrated the synthesis of iron oxide nanoparticles (IONPs) by utilizing spinach powder and BC (black coffee) extract at various microwave powers i.e., $100 \mathrm{~W}-1000 \mathrm{~W}$. The findings of this study indicate the improved efficacy of microwave assisted IONPs in subduing fungal growth and enhancing plant growth, both under in-vitro and in-vivo conditions. In addition, alternations in mycelia, ROS production, membrane integrity and DNA fragmentation were evaluated in fungal pathogen. Importantly, the effects of IONPs on plant germination, disease index, enzymatic and non-enzymatic antioxidant enzymes were also measured. These findings provide significant information on efficient supply and activation of defensive pathways in tomato plants in response to metal oxide exposure and has a potential to replace the conventional chemicals, which are also toxic to the environment.

\section{Materials And Methods}

\section{Materials, reagents and fungal culture}

All the reagents and chemicals were of analytic grade, obtained from Sigma-Aldrich, (St Louis, MO, USA) consumed without any further purification unless otherwise specified. Fresh spinach leaves (Spinacia oleracea), bought from local vegetable market of Lahore, Pakistan, were used as a starting material. Black coffee extract was prepared by dissolving $20 \mathrm{~g}$ of coffee powder to $100 \mathrm{~mL}$ of deionized water (DI) by adjusting $\mathrm{pH}$ at 5. Tomato seeds were obtained from Ayub Agriculture Research Institute (AARI), Faisalabad, Pakistan. "Fusarium oxysporum f. sp. lycopersici (IAGS-1322)" used in this investigation as a challenging tomato pathogen, issued by Fungal-Biotechnology-Lab, Department of Plant Pathology, Faculty of Agricultural Sciences, University of the Punjab, Lahore, that was previously isolated from infected tomato fields and was preferred, based on its virulence. Stock culture was grown and maintained on potato dextrose agar (PDA) slants at $4{ }^{\circ} \mathrm{C}$ for long term use. For solid cultures of $F$. oxysporum, stock 
cultures were sub-cultured onto Petri plates having PDA and left for 7 days in dark at $28^{\circ} \mathrm{C}$. Deionized water was used as a solvent.

\section{Green synthesis of Iron oxide Nanoparticles (IONPs)}

For the synthesis of IONPs, spinach (Spinacia oleracea) was used as a staring material. Initially, spinach leaves were washed with deionized water and further dried at room temperature $\left(25^{\circ} \mathrm{C}\right)$ for $2 \mathrm{~h}$. Dried leaves were kept in muffle furnace at $500^{\circ} \mathrm{C}$ for $2 \mathrm{~h}$ to get powdered leaves. Nano ball milling was performed for $4 \mathrm{~h}$ at $3000 \mathrm{rpm}$ in pulverisette (Fritsch pulverisette-23 mini mill) to obtained fine nanopowder. Four grams $(4 \mathrm{~g})$ of nano milled powder was dissolved in $400 \mathrm{~mL}$ of DI water under vigorous stirring (solution A). Black coffee (BC) extract was added dropwise to solution 'A' to prepare $0.01 \mathrm{M}$ solution (solution 'B') under continuous stirring. Solution 'B' was further subjected to various microwave powers i.e., $100 \mathrm{~W}-1000 \mathrm{~W}$, for the formation of stabilized iron-oxide powder. On and off time of microwave was precisely controlled to overcome the spitting process due to localized heat generated in microwave oven. The resultant product was separated by centrifugation and dried in vacuum oven $80^{\circ} \mathrm{C}$ for further characterization. Details regarding characterization instruments is discuss in Experiment S1. The schematic is shown in Fig. 1.

\section{Inhibitory effect of Iron-oxide nanoparticles on fungal mycelial growth}

In vitro antifungal activity of Iron-oxide nanoparticles on mycelial growth of $F$. oxysporum was evaluated by following agar dilution protocol. Twenty milliliter of PDA was poured into sterilized Petri dishes and measured amount of IONPs from stock solution was added to get the required concentrations. The final concentrations in the growth media were $0.01,0.5,1.5,2.5,5,7.5,10,12.5$ and $15 \mu \mathrm{g}$ of IONPs per $\mathrm{mL}$. PDA plates without IONPs were used as a negative control while plates with fungicide treatment serves as positive control. Afterwards, fungal disc ( $4 \mathrm{~mm}$ in diameter) was incised from the fringe of a seven-day old culture of F. oxysporum and inoculated aseptically at the center of each PDA solid media plate. Later, plates were sealed and incubated at $28^{\circ} \mathrm{C}$ until the growth in the control plates extends to periphery. Each treatment was performed in triplicates. Photographs were captured and mycelial radial growth was estimated after 7 days. Percentage inhibition of radial growth by different concentrations of iron-oxide nanoparticles in comparison to control was calculated using equation (1):

Percent Inhibition Radial Growth $(\%)=\left[\left(\mathrm{R}_{1}-\mathrm{R}_{2}\right) / \mathrm{R}_{1}\right] \times 100$

Where,

$\mathrm{R}_{1}$ : mean radial growth in control group, $\mathrm{R}_{2}$ : mean radial growth in treatment group [30]. The protocol for determining suppressive activity of IONPs on fungal spore germination is discussed in Experiment S2.

\section{Evaluating morphological alterations in fungal mycelia by SEM}

The morphological and ultrastructural changes in fungal hypha after treatment with IONPs were examined by Field-emission-scanning-electron-microscope (FE-SEM). In brief, control and nanoparticles 
treated F. oxysporum ( 10 and $15 \mu \mathrm{g} / \mathrm{mL}$ ) mycelium, were scratched out and fixed for $4 \mathrm{~h}$ with glutaraldehyde $(2.5 \%)$ at $4{ }^{\circ} \mathrm{C}$, post-fixed with aqueous-osmium-tetroxide (1\%), later the fixed sample was washed for several times with phosphate-buffer-saline $(\mathrm{pH}: 7,0.5 \mathrm{M})$. Afterwards, the hyphal samples were exsiccated with ethanol in form of gradient-series (30\%: 50\%: $70 \%: 80 \%: 90 \%$ and $100 \%$ ), twenty min per series. Subsequently, hyphal sections were left overnight in isoamyl-acetate. Finally, the sections were exposed to analytical level of dry $\mathrm{CO}_{2}$, conductively coated by gold sputter and observed under a FE-SEM (S-4800, Hitachi-Japan).

\section{Evaluating Reactive oxygen species (ROS) production}

For analysis of the oxidative stress in fungal hyphae induced by iron oxide nanoparticles, was detected by a redox sensitive fluorescent-probe, 2',7'-dichloro-dihydro-fluorescein-diacetate $\left(\mathrm{H}_{2} \mathrm{DCFDA}\right)$ by following the protocol of Chen et al. [26] with some modifications. Briefly, F. oxysporum mycelium cultured in PDB (Potato dextrose broth) amended with three different concentrations of IONPs (5, 10 and $15 \mu \mathrm{g} / \mathrm{mL}$ ) for twenty-four hours at $28^{\circ} \mathrm{C}$. Later, hyphae amassed through centrifugation for $10 \mathrm{~min}$ at $3500 \mathrm{rpm}$ by discarding the media. Subsequently, mycelia were washed and resuspended in PBS. Afterwards, samples were stained for 20 min with $10 \mu \mathrm{M} \mathrm{H}_{2}$ DCFDA under dark conditions at room temperature. Percentage of intra-cellular ROS in IONPs-treated mycelial samples was calculated with respect to the un-treated control (100\%). For visual detection of ROS production in fungal mycelium was observed by confocal-laser scanning-fluorescence microscope (CLSM, Zeiss LSM 7) with emission at $525 \mathrm{~nm}$ and excitation at 488 $\mathrm{nm}$. The quantification of fluorescence intensity was carried out by using Image $\mathrm{J}$ software [31].

\section{Evaluating plasma membrane integrity}

Integrity of plasma membrane of $F$. oxysporum after treatment with IONPs were explored by propidium iodide (PI: membrane-impermeable dye) according to the earlier protocol described by Wei et al. [32] with minor modifications. Fungal mycelia were collected by following the above protocol. The suspension was not treated with nanoparticles considered as control. Subsequently, collected mycelia were stained with $10 \mu \mathrm{g} / \mathrm{mL}$ od PI for $15 \mathrm{~min}$ at $30^{\circ} \mathrm{C}$ under dark conditions. After centrifugation at $5000 \mathrm{rpm}$ for $5 \mathrm{~min}$ at 4 ${ }^{\circ} \mathrm{C}$, mycelia were rinsed twice with 0.5 M PBS ( $\left.\mathrm{pH}: 7\right)$ to eradicate residual-dyes and re-suspended in the same buffer. Samples were observed by confocal-laser scanning-fluorescence microscope (CLSM, Zeiss LSM 7) with emission at $617 \mathrm{~nm}$ and excitation at $536 \mathrm{~nm}$, while results were analyzed in percentage with reference to the control. The quantification of fluorescence intensity was carried out by using Image J software.

\section{Analyzing genomic DNA fragmentation}

The fresh fungal culture treated with different concentrations $(0.1-15 \mu \mathrm{g} / \mathrm{mL})$ of iron-oxide nanoparticles, centrifuged (10 min; $12,000 \mathrm{rpm} ; 4^{\circ} \mathrm{C}$ ) to get pellet and lysed with lysis buffer (10 mM-EDTA, $0.5 \%$-Triton $\mathrm{X}-100,0.1 \mathrm{M}-\mathrm{NaCl}, 10 \mathrm{mM}-\mathrm{Tris}-\mathrm{HCl}, 2 \%-\mathrm{SDS}, \mathrm{pH}: 7.5)$. This mixture was incubated for $30 \mathrm{~min}$ at $37^{\circ} \mathrm{C}$.

Next, the lysates were incubated with RNase $(0.03 \mathrm{mg} / \mathrm{L})$ and proteinase $\mathrm{K}(0.2 \mathrm{mg} / \mathrm{mL})$ solution at $55^{\circ} \mathrm{C}$ for 1 hour. After incubation period, the concoction was centrifuged for ten minutes at 10,000 rpm. The 
nuclear-DNA of $F$. oxysporum was then isolated by using phenol-chloroform mixture. The aqueous phase was then transferred to new tube and purified with isopropanol and placed at $-20^{\circ} \mathrm{C}$ for $20 \mathrm{~min}$. The DNA samples were rinsed thrice with $70 \%$ ethanol and resuspended in TE buffer. DNA samples were run on a $1 \%$ agarose gel in $1 \times$ TAE buffer at 100 volts for 60 min stained with ethidium bromide $(1 \mathrm{mg} / \mathrm{mL})$. The gel photographs were captured by using UV-transilluminator (Witeg, Germany).

\section{Evaluating the impact of IONPs under green-house assay}

A tomato variety (Rio-Grande) susceptible to wilt disease caused by F. oxysporum were grown in small plastic pots under controlled conditions (temp: $30-28 \pm 1^{\circ} \mathrm{C}$; humidity $85-90 \%$ ) for $25-30$ days, until 3-5 leaves were developed. The fungal pathogen i.e., Fusarium oxysporum was grown on potato dextrose broth (PDB) to develop conidial suspension, while inoculated concentration was adjusted to be $1 \mathrm{x}$ $10^{6} \mathrm{spore} / \mathrm{mL}$. Specifically, one week before seedling transplantation, each plastic pot filled with sterilize soil, received $30 \mathrm{~mL}$ of spore suspension in a separate trial. Nanoparticle's treatment was performed by root dipping method [33] by keeping tomato plant roots in various concentrations of IONPs (0.1-15 $\mu \mathrm{g} / \mathrm{mL}$ ) at room temperature. Afterwards, uniform tomato seedlings were shifted to infected soil, three plants per pot. Positive and negative controls treated with fungicide (Nativo) and sterilized water. Foliar applications of nanoparticles sprays with interim of five days were performed after two weeks of transplanting. Each treatment was adjusted by three replicates. The Fusarium wilt disease incidence (DI) and percent disease severity (PDS) was evaluated after 25 days of post inoculation. The disease severity for FW (Fusarium wilt) on tomato plants was determined using the following 0-6 indexing scale with minor modifications [34].Disease severity scale: (1 = Immune: symptomless, 2= Resistant: Initiation of wilting symptoms, $5 \%$ leaves showing yellowing and wilting, 3= Moderately Resistant: 6-10\% wilting and yellowing of leaves, $4=$ Moderately susceptible: $11-12 \%$ leaves show symptoms, $5=$ Susceptible: $21-50 \%$ leaves showing wilting with yellow brown bicolouration, and $6=$ Highly susceptible: $>50 \%$ leaves show infection, dying and drying of plant. Percentage disease severity was calculated by using the following equation (2):

Disease severity $(\%)=\sum[(n \times V) /(6 \times N)] \times 100$

Where, $\mathrm{n}$ : number of diseased plants, $\mathrm{V}$ : numerical grade of diseased plants, $\mathrm{N}=$ total number of plants examined in each treatment, $6=$ the highest grade of infection category.

While disease incidence (DI) was calculated using equation (3):

Disease incidence $(\%)=$ No. of diseased plants $/$ Total no. of plants $x 100$

Methods to evaluate physiological and biochemical variations in tomato roots and shoots after treatment with different concentrations of IONPs are discussed in Experiment S3. After 60 days of transplantation, tomato plants were carefully uprooted to calculate growth variables such as, plant height, length (root \& shoot) and plant biomass (fresh \& dry weight). 


\section{Statistical analysis}

Statistical-analysis was achieved by using GraphPad-Prism (8.4.3) software (GraphPad-software, CA, USA). One-way-analysis-of-variance (ANOVA) or students t-test was employed for comparing means and difference between group mean, by using Tukey's multiple comparison test. The outcomes were presented as the mean \pm standard-deviation (SD) for three or more replicates. Asterisks $\left({ }^{*} P<0.05 ;{ }^{* \star} P<\right.$ $0.01 ; * \star \star P<0.001)$ represents significant differences.

\section{Results And Discussion}

\section{Structural analysis of green synthesized IONPs}

XRD patterns of iron oxide nanoparticles (IONPs) synthesized by using spinach leaves and (black coffee) $\mathrm{BC}$ extract, subjected to various microwave powers i.e., $100 \mathrm{~W}$ to $1000 \mathrm{~W}$ (Fig. 2). XRD results demonstrated the presence of phase pure spinal structured magnetite nanoparticles for all of the microwave powers. Peaks exhibiting at $2 \theta$ angle of $30.02^{\circ}, 35.64^{\circ}, 43.44^{\circ}, 49.79^{\circ}, 54.1^{\circ}, 57.35^{\circ}, 62.72^{\circ}$ and $64.18^{\circ}$ corresponds to diffraction planes of (202), (311), (400), (313), (422), (511), (404) and (531). The peaks of $\mathrm{Fe}_{2} \mathrm{O}_{3}$ nanoparticles were index with JCPDS card no. 19-629. In present study, BC was utilized as reducing agent. Major constituents of $\mathrm{BC}$ are caffeine and tannin. Tannins are composed of polyphenolic compounds (non-toxic) which are reducing and stabilizing agents for the synthesis of IONPs. The phenolic-OH as well as ortho-dihydroxyphenyl groups present in the chemical structure of tannins are responsible for complex formation with iron. These groups also participate in redox reactions [35]. Therefore, production of $\mathrm{Fe}_{3} \mathrm{O}_{4}$ nanoparticles is mainly governed by the tannins present in $\mathrm{BC}$ extract. Also, the use of microwave radiation makes it possible to synthesize pure phase $\mathrm{Fe}_{3} \mathrm{O}_{4}$ nanoparticles without any further heat treatment. Microwave energy is converted into heat energy which is highly depends upon the nature of utilizing solvent. The parameter which determines the capability of material for this conversion is termed as "tangent loss" (tan $\delta)$. Usually for microwave radiations having typical frequency of $2.45 \mathrm{GHz}$, solvents with higher value of $\tan \delta$ are preferable choice as they can absorb excellent amount of radiations thus convert it into heat energy [36]. Due to higher tangent loss of polyphenols (i.e., constituents of $\mathrm{BC}$, tannin), high heat will be produced in microwave oven thus leading towards the phase pure $\mathrm{Fe}_{3} \mathrm{O}_{4}$ nanoparticles even without further heat treatment.

Crystallite size (t) and dislocation density ( $\delta$ ) were plotted (Figure S1) and calculated using Eqs. (4-5), respectively [37].

$$
\begin{gathered}
\mathrm{t}=\frac{k \lambda}{B \operatorname{Cos} \theta} \\
\delta=\frac{1}{\mathrm{t}^{2}}
\end{gathered}
$$


Where, $\mathrm{k}$ is shape factor taken as $0.9, \lambda$ is the wavelength of Cu ka source, $\beta$ is full width at half maximum (FWHM), $\theta$ is the diffraction angle of highest intensity peak. Variation in crystallite size was observed with the variation in various extracts used during microwave powers. Black coffee along with microwave heating played a critical role not only in achieving $\mathrm{Fe}_{3} \mathrm{O}_{4}$ phase of iron oxide (Fig. 2) but also in achieving a small value of crystallite size (Figure S1). XRD analysis also revealed that synthesized nanoparticles using $100 \mathrm{~W}-200 \mathrm{~W}$ power possess amorphous behavior while for higher microwave powers crystalline nature of iron oxide nanoparticles along with phase stability was observed (Fig. 2). Major factors influencing crystallite size are lowest surface energy, grain boundary energy and diffusion of surface atoms. Microwave energy was observed to be effective to tune these parameters thus leading to formation of stabilized and pure phased $\mathrm{Fe}_{3} \mathrm{O}_{4}$ nanoparticles. Highest crystallite size i.e., $\sim 15 \mathrm{~nm}$ along with lowest dislocation value was observed after using microwave power of $1000 \mathrm{~W}$ (Figure S1).

\section{Dielectric analysis of green synthesized IONPs}

Short ranged electrical conduction of material is dependent on the dielectric properties which it exhibits. Charged particles in the material experience a displacement as a result of applied electric field and gets pile up at the interfaces and hence creation of dipoles takes place. Frequency dependent dielectric constant of iron oxide nanoparticles (IONPs) was obtained by impedance analyzer using Eq. (6), whereas the tangent loss was calculated using Eq. (7) [38].

$\varepsilon=(C \mathrm{~d}) / \varepsilon_{0} \mathrm{~A}$

$\tan \delta=1 /\left(2 \pi f \varepsilon \varepsilon_{0} \rho\right)$

Where, ' $C$ ' represents capacitance, ' $d$ ' is for specimen's thickness, ' $A$ ' is for area, ' $\rho$ ' is for resistivity and permittivity of free space is represented by ' $\varepsilon_{0}$ '.

Variation in dielectric constant and tangent loss as function of frequency at room temperature was shown in Fig. 3A, B. Different types of polarization i.e., ionic, electronic, orientational and dipole are accompanied with dielectric constant under the effect of an alternating electric field. At low frequency space charge polarization is dominant whereas, at high frequency ionic and electronic polarizations dominate in polycrystalline material. When an external electric field is applied dispersion occurs in space charges and these space charges require some time to align themselves in the direction of applied field. At low frequency space charges get enough time for their arrangement as per applied field. However, at high frequency values charges do not get enough time to orient themselves in the direction of the applied field, thus, resulting in low dielectric values (Fig. 3A). Dielectric constant almost remained same for samples synthesized with low microwave powers i.e., $100 \mathrm{~W}-200 \mathrm{~W}$. Small values of dielectric constant at low microwave power is due to amorphous behaviour of iron oxide nanoparticles as observed in XRD patterns (Fig. 2). Whereas increase in dielectric constant was observed with the increase in microwave power from $300 \mathrm{~W}-1000 \mathrm{~W}$. High value of dielectric constant is attributed to the presence of both $\mathrm{Fe}^{3+}$ and $\mathrm{Fe}^{2+}$ cations in $\mathrm{Fe}_{3} \mathrm{O}_{4}$ phase of iron oxide. Heterogeneity in $\mathrm{Fe}_{3} \mathrm{O}_{4}$ structure arises because of the 
existence of $\mathrm{Fe}^{2+}$ cations that gives high polarization, leading to higher value of dielectric constant $[39,40]$. High dielectric constant can be employed in agricultural field i.e., plant pathology for investigating activities of pathogenic microbes including fungi.

Tangent loss for as synthesized nanoparticles is shown in Fig. 3B. The plot of tangent loss shows normal dispersion behaviour due to space charge polarization. Relatively, higher values of tangent loss are observed for nanoparticles prepared at low microwave power i.e., $100 \mathrm{~W}-200 \mathrm{~W}$ whereas, low values of tangent loss are observed for high microwave powers. Comparison of dielectric constant as well as tangent loss with respect to varying microwave powers at $\log f=5$ and $\log f=1.3$ (Figure S2).

Conductivity of as synthesized nanoparticles of IONPs are calculated by Eq. (8) [38].

$$
\sigma=2 \pi \tan \delta f \varepsilon \varepsilon_{0}
$$

Conductivity is categorized in two regions, i.e., low frequency region and high frequency region. At low frequency region conductivity is known as dc-like conductivity because of free charge carriers. Whereas, at high frequency it is known as ac conductivity because of bound charge carriers. Figure S3A shows variation in conductivity as a function of frequency for all of the samples prepared using various microwave powers i.e., from $100 \mathrm{~W}-1000 \mathrm{~W}$. Small values of conductivity, because of the hopping mechanism of charge carriers, are observed even at high frequency values. Comparison of conductivity values at $\log f=5$ and $\log f=7.3$ by using various microwave powers is exhibited in Fig. S3B.

Impedance is a property that offered an opposition to the flow of electric current. Conduction in nanomaterials can be best comprehended on the base of complex impedance spectroscopy which is an effective technique to differentiate the resistive and conducting elements in the circuit. Complex impedance ( $\left.Z^{*}\right)$ is presented in Eq. (9) [38] while real ( $\left.Z^{\prime}\right)$ and imaginary ( $\left.Z^{\prime \prime}\right)$ impedance are given in Eq. (10) and (11) respectively [38].

$Z^{*}=Z^{\prime}-j Z^{\prime \prime}$

$Z^{\prime}=Z \cos \theta$

$Z^{\prime \prime}=Z \sin \theta$

The variation of real and imaginary impedance in iron oxide nanoparticles with respect to frequency is depicted in Fig. 4A,B. Two regions are observed in Z' plots (Fig. 4A). First is the region of low frequencies in which there is a slight decrease in $Z^{\prime}$. Second is the region in which $Z^{\prime}$ decreases monotonically and becomes constant at higher frequencies. This behavior is connected with conductivity of charge carriers observed in Fig. 4A where conductivity increases at high frequencies [41,42]. Z" (Fig. 4B) shows different relaxation peaks at different values of frequency for changes in microwave powers. Information regarding grains and interface effects in poly crystalline materials can be realized on the basis of these relaxation peaks which demonstrate different relaxation mechanism happening in nanoparticles [42]. 
Relaxation peaks at different microwave powers spread in different zones of frequency explains the distinguished participation of grains and grain boundaries. To obtain the exact contribution of grains and grain boundaries towards the conduction process Cole-Cole plots i.e., plots between Z" and Z' were studied (Fig. 4C). Generally, Cole-Cole plot contain of three semi circles. First semi-circle in high frequency regime represents the effect of grains resistance, second semicircle in the middle range of frequency correspond to grain boundary resistance and the third one in low frequency range represents the resistance offered by grain-to-grain boundary interface. These plots provide information about electrical characteristics of material (grains and grain boundaries) [43].

\section{FTIR analysis of green synthesized IONPs}

FTIR spectra of green synthesized IONPs using BC extract and dried using various microwave powers is depicted in Fig. 5A,B. Peak appeared at $\sim 560 \mathrm{~cm}^{-1}$ was assigned to characteristic band of Fe-O that also in well agreement with previously reported literature [44]. The band at $1068 \mathrm{~cm}^{-1}$ was appeared due to $\mathrm{C}-\mathrm{N}$ stretching. While, peaks appearing at $1561 \mathrm{~cm}^{-1}$ and $1650 \mathrm{~cm}^{-1}$ were ascribed to $C=C$ stretching vibrational bands due to presence of aromatic rings / phenolic groups present in $\mathrm{BC}$ extract. Presence of phenolic feature indicates the capping effect on the surface of IONPs. Absorption band appeared at 2352 $\mathrm{cm}^{-1}$ corresponds to atmospheric $\mathrm{CO}_{2}$ [45].

\section{Magnetic response of green synthesized IONPs}

Superparamagnetic response of green synthesized IONPs at various microwave powers i.e., $100 \mathrm{~W}-1000$ W, was detected through M-H loops (Fig. 6). However, high saturation magnetization $(\sim 21.72 \mathrm{emu} / \mathrm{g})$ was observed for IONPs synthesized at $1000 \mathrm{~W}$ (Fig. 6J). Superparamagnetic behavior arises when size of single domain becomes so small that thermal energy can easily overcome anisotropy energy barrier. As the particle size is decreased number of surface spins contributing to magnetization increases [46]. Such behavior of IONPs makes it potential candidate for agricultural applications in terms of targeted delivery of nutrients and controlled release of pesticides in plant. Variation in saturation magnetization (Ms) was observed by using various microwave powers (Figure S4).

\section{X-ray photoelectron spectroscopic (XPS) analysis of green synthesized IONPs}

XPS analysis of IONPs was performed by using spinach as a precursor along with black coffee (BC) extract at various microwave powers (100 W-1000 W) with interval of $100 \mathrm{~W}$ (Fig. $7 \mathrm{~A}, \mathrm{~B})$. It can be observed that binding energy peaks of $\mathrm{Fe} 2 \mathrm{p}_{3 / 2}$ and $\mathrm{Fe} 2 \mathrm{p}_{1 / 2}$ at $710.9 \mathrm{eV}$ and $724.5 \mathrm{eV}$ are due to magnetite $\left(\mathrm{Fe}_{3} \mathrm{O}_{4}\right)$, respectively (Fig. $\left.7 \mathrm{~A}\right)$ [47]. Splitted spin-orbit peak of $\mathrm{Fe} 2 \mathrm{p}$ are wide due to less chemical shift between $\mathrm{Fe}^{2+} \& \mathrm{Fe}^{3+}[48]$. Figure. $7 \mathrm{~b}$ represents the spectra of 01s core level. Peak present at $529.9 \mathrm{eV}$ is due to existence of $\mathrm{O}^{-2}$ species and $531.7 \mathrm{eV}$ is due to existence of $\mathrm{OH}^{-}$species present on iron oxide surface. Other peak at $532.9 \mathrm{eV}$ is associated with adsorbed $\mathrm{H}_{2} \mathrm{O}$ molecules [49].

\section{Surface morphology and size distribution of green synthesized IONPS}


The benefits of using microwave-assisted approach in contrast to chemical-methods includes in-core heating of materials in a rapid way and its specific chemical bonds gives discerning absorbance, which results as nano size particles, having uniform size and shape, depicted from microscopic images (SEM and TEM). The morphology and particle size distribution of green synthesized iron oxide nanoparticles (IONPS) at $1000 \mathrm{~W}$ power were revealed by SEM and TEM analysis (Figure S5). Microscopic images indicate uniform, spherical, polydisperse, less-aggregated crystalline nature of IONPs (Figure S5 A, C) which endorses the purity of the sample without any other phases. Figure S5B showed the particles size distribution of IONPs by SEM, was in the range of 3-23 nm with an average diameter of $4.99 \pm 0.17 \mathrm{~nm}$. Correspondingly, the mean particle size of $4.08 \pm 0.19 \mathrm{~nm}$ was determined by TEM, varying from 1-15 nm, conferring to Gaussian fit of particle size distribution (Figure S5D). These results display the narrow size distribution of green synthesized IONPs, which are somehow coherent with previous studies [50-53].

\section{IONPs as inducer of antifungal activity-inhibiting fungal growth and spore germination}

We investigated the in-vitro antifungal activity of biosynthesized iron oxide nanoparticles (IONPS) synthesized at various microwave powers ( $100 \mathrm{~W}-1000 \mathrm{~W})$ as shown in Table S1. After initial screening, the IONPs at 1000W was selected and used for next experiments which also justify the phenomena of highest magnetic saturation at this microwave power. The emergence of resistance in plant fungal pathogens against agrochemicals leads towards development of more efficient antifungal agents which must be eco-friendly. Therefore, antifungal potential of nanoparticles is beneficial in agriculture sector as they emerged as "innovative-generation fungicides" [54]. Figure 8 shows the effect of INOPs on fungal mycelial growth and spore germination at various tested concentrations $(0.01 \mu \mathrm{g} / \mathrm{mL}-15 \mu \mathrm{g} / \mathrm{mL})$ against F. oxysporum, the causal agent of tomato wilt.

IONPs exhibited strong inhibitory effect on radial growth of fungal mycelia on PDA medium as compared with control treatment (Fig. 8A). It is evident from the results that antifungal activity of iron oxide nanoparticles significantly increases in a dosage-dependent form. After seven days of post inoculation, $15 \mu \mathrm{g} / \mathrm{mL}$ of IONPs strikingly minimized $F$. oxysporum growth by $90.84 \pm 0.56 \%$, in contrast to the control treatment. For lower concentrations, ranges from $0.01-1.5 \mu \mathrm{g} / \mathrm{mL}$, displayed minimum growth inhibition i.e., below $50 \%$ whereas, fungicide exposure yielded $89.771 .24 \%$, relative to the growth rate in control group (Fig. 8B). Former studies indicated the antimicrobial activity of IONPs, and their finding suggests that this activity increases gradually from lower to higher concentration [55, 22-23].

The sporicidal activity of IONPs on spore's germination of F. oxysporum was illustrated in Fig. 8C,D. Disruption of fungal membrane indicates the inhibiting action of nanoparticles as observed in this study is owing to the biocidal action of nanoparticles, furthermore, smaller size NPs retain large surface area gets readily attached and absorbed to disassemble the microbial cell membrane, leads to deterioration of intracellular organelles, eventually results in death of microorganism [56,57]. After six hours of incubation with various concentrations of iron oxide nanoparticles, the microscopic images revealed that spore suspension of $F$. oxysporum displayed a sharp decline in spore germination rate in contrast to the untreated control samples (Fig. 8D). In fungal life cycle, spore germination and maturation are vital 
phases for successful plant colonization, but once the germination is subdued after treated with graphene oxide, spore cannot develop into mature mycelium to initiate the infection cycle [35]. It can be clearly indicated from the results that germination rate of spores was gradually reduced in response to the increasing concentrations. A statistically significant reduction in germination rate was observed at concentrations ranges from $1.5-15 \mu \mathrm{g} / \mathrm{mL}$, while minimum germination rate was up to $5.38 \pm 1.38 \%$ at $15 \mu \mathrm{g} / \mathrm{mL}$ in comparison with the control group (88.58 $\pm 0.69 \%)$. Analogously, in case of fungicide, significant inhibition to spore germination was determined to be $18.56 \pm 0.86 \%$ respectively (Fig. $8 \mathrm{C}$ ). Devi et al. worked on two fungal species (A. niger and $M$. piriformis) proposed that greater surface interaction among iron oxide nanoparticles and fungal membranes played a significant role in antifungal activity [58]. Analogously, Saleem et al. also exhibited antifungal potency of green synthesized iron-oxide nanoparticles against $A$. flavus and F. oxysporum, their finding suggests that IONPs have potential to be used for biological applications [59].

\section{IONPs induce changes in cell-wall morphology, viability and ROS production in F. oxysporum}

The SEM micrographs revealed malformed mycelium after treatment with iron oxide nanoparticles can be attributed to distortion of chitin synthesis and cell envelop; that shields the leakage of cellular component into extracellular environment [19]. SEM visualization indicates the detrimental effects of iron-oxide NPs on F. oxysporum. The IONPs treated mycelia revealed some eccentric morphological characteristics as compared to the control (Fig. 9A). In control, cylindrical shaped mycelium has healthy smooth turgid surface with clear conidiation (Fig. 9A-a). Whereas, after contact with IONPs, the remarkable structural changes were induced in fungal hyphae as observed in Fig. 9A-b,c. At $10 \mu \mathrm{g} / \mathrm{mL}$, hypha became deformed showing irregular shrinkage with minute granules on surface (Fig. 9A-b). The impairment was intensified at $15 \mu \mathrm{g} / \mathrm{mL}$, the hyphae become recessed, slender and stacked together including rifts or blebs (Fig. 9A-c). Earlier investigations suggested that consecutive interactions occurred due to magnetic nanoparticles which stimulated microbial toxicity, such as discharging of metal-ions, affecting protein synchronization and cellular-homeostasis; lipid-peroxidation and nucleic acid impairment by accumulation of reactive oxygen species (ROS) and mutilation of cell integrity by membranedepolarization [60].

The antifungal property of IONPs was further verified by using fluorescent dyes i.e., Propidium iodide (PI) and 2',7'-dichloro-dihydro-fluorescein-diacetate $\left(\mathrm{H}_{2} \mathrm{DCFDA}\right)$. The fluorescence intensity of fungal hyphae was significantly enhanced in dose-dependent manner on the treatment of IONPs in contrast to the untreated control. Alike outcome was perceived for IONPs bound with amphotericin B, by a reaction between aldehyde and amine groups against candida strains [61]. Propidium iodide is a DNA-fluorescentprobe that invades disrupted plasma membrane of cell, emitting red color fluorescence from stained nucleus [62]. The effect of IONPs on membrane integrity of $F$. oxysporum in control and treated fungal mycelial samples were depicted in Fig. 9B. As pragmatic from the RFP (red fluorescence protein) images a slight red-fluorescence was detected in the control hyphae whereas, stronger fluorescence was observed in treated ones. After 15 mins of exposure, the PI fluorescence intensity in treated groups (5,10 and 15 $\mu \mathrm{g} / \mathrm{mL}$ ) were 2.21, 3.09 and 3.69 folds, significantly higher than the control group (Fig. 9D). The GFP 
(Green fluorescence protein) micrographs of control and IONPs treated fungal mycelia of ROS accumulation were illustrated in Fig. 9C. Treatment of $F$. oxysporum with 5,10 and $15 \mu \mathrm{g} / \mathrm{mL}$ of IONPs significantly increased $\mathrm{H}_{2}$ DCFDA fluorescence intensity by 2.07, 2.73 and 3.05 times than the control (Fig. $9 \mathrm{E})$. Cell genotoxicity and cytotoxicity affected by the surface charge of IONPs, furthermore, NPs with positive charge acts to be more lethal, endures adsorptive endo-cytosis and nonspecific-interactions with the negatively charged cell-membrane, hence distressing the membrane permeability by enhancing intracellular-accumulation [63]. Thus far, it is documented that IONPs reveals antimicrobial affects by inducing production of reactive oxygen species (ROS), following disruption of microbe's electrontransport, NADH oxidation and cellular- homeostasis thus contributing towards anti-fungal effects. ${ }^{64}$ No doubt, magnetic oxide nanoparticles retain the ability to aggravates oxidative stress by disturbing the redox potential of cells additionally, augmenting the host antimicrobial resistance by targeting the infection sites with direct approach to eradicate microbial pathogens $[61,65]$.

Our results indicate that IONPs inactivates the oxidation reduction balance by generating ROS, maybe associated with action mechanism of magnetic NPs, outcomes as pore-formation in cell membrane and stipulates to transports nanoparticles into Fusarium cells. Earlier reports unveiled that cell after uptake of IONPs produces ROS via either pathway: Iron ions contributes in the Haber-Weiss cycle by releasing ions into cytosol where chelation by adenosine-phosphate or citrate occurs or the surface of IONPs catalyzed Fenton reaction or Haber-Weiss cycle that could have a detrimental effect on fungal cells while highly reactive-hydroxyl radical is formed as a result of both pathways [66]. By comparing the fluorescence intensities as shown above specifies that the fungal-nano interactions were relatively stronger after treatment with IONPs that eventually increases the variation in free-energy content, resulting more ROS generation. In line up with current investigation, Arakha et al. found that chitosan-coated IONPs in culture media has ability to enhance ROS production by altering the interaction pattern among bio-nano interface, plays a critical role for antimicrobial affinity of iron oxide NPs [27].

\section{IONPs as inducer of DNA-fragmentation in F. oxysporum}

DNA-fragmentation is another biochemical key feature of apoptosis (programmed-cell-death) [67]. The inter-nucleosomal cleavage of genomic DNA was studied in F. oxysporum subjected to various concentrations of IONPs. DNA was isolated from fungal cells and analyzed by agarose gel electrophoresis. The electro-phoretogram is presented in Figure S6. As it is clear from the gel image that typical DNA ladder were formed in control group however "DNA-laddering" of non-chronological DNA fragments were found in IONPs treated group. Moreover, it can be observed that DNA-cleavage increases in IONPs treated samples in concentration-dependent manner. Gel containing DNAs of $F$. oxysporum also indicates single high molecular-DNA-bands in lanes 1,2 and 3 , treated with $0.01,0.5$ and $1.5 \mu \mathrm{g} / \mathrm{mL}$ IONPs. However, the intensities of these DNA-bands were less than the control group (lane 10). Additionally, the smeared-DNA in all lanes is less than $1 \mathrm{~Kb}$ and apparently appears weaker than the control. Smeared-DNA almost disappears in lane 8 and 9, implying that IONPs completely impaired the fungal DNA. The results indicated that antifungal effect of IONPs on fungal cells was triggered through the initiation of cell-apoptosis. Alarifi et al. observed breakage of DNA double helix strand by iron-oxide 
nanoparticles in time and dose-dependent manner [68]. ROS is reported to be implicate in DNA mutilation by IONPs effecting DNA bases such as pyrimidine and purine, contributing to reduce the biofilm formation in bacterial cell [29].

\section{Impact of IONPs on tomato growth-parameters}

All concentrations of Iron oxide nanoparticles $(0.01-15 \mu \mathrm{g} / \mathrm{mL})$ significantly enhanced the growth parameters (length (root and shoot), biomass (fresh and dry weight) and plant height of tomato plants infected with Fusarium wilt under pot bioassay (Fig. 10: Figure S7). Root-shoot length and germinationrate are the chief indicators to investigate the impact of nanoparticles in different plant species [69]. The concentration at $12.5 \mu \mathrm{g} / \mathrm{mL}$ revealed the best results by depicting a substantial increase in growth attributes in comparison to the control and other treatments. A gradual increase in plant height was observed for all treatments however, plants treated with $10,12.5$ and $15 \mu \mathrm{g} / \mathrm{mL}$ of IONPs showed the maximum plant height of 45.1, 48.9 and $43 \mathrm{~cm}$ (Figure S7A), exceeding the control treatment by $64 \%$, $77.8 \%$ and $56.3 \%$ respectively. Similarly, consistent result was observed for fungicide with an increase of $51.6 \%$. Correspondingly, root and shoot length of plants were substantially improved after the treatment of IONPs (Figure S7B). Furthermore, the average root and shoot length under $5-15 \mu \mathrm{g} / \mathrm{mL}$ were greatly analogous to the control treatment, predominantly for $12.5 \mu \mathrm{g} / \mathrm{mL}$ showed an increase of $76.3 \%$ (roots) and $79.05 \%$ (shoots) respectively. Moreover, statistically significant difference was found for plant biomass (fresh and dry weight) in contrast to the control treatment (Figure S7C). The fresh and dry weight was superior with $12 \mu \mathrm{g} / \mathrm{mL}$ treatment surpassing the control by $60.9 \%$ and $67.1 \%$. While fungicide treatments followed the same trend for fresh and dry weight by showing an increase of $43.8 \%$ and $47.7 \%$, with respect to the control. Earlier studies reported increase in seed germination, plantbiomass, seedling growth/vigor and yield after application of iron oxide nanoparticles [70-74]. Treatment of tomato seeds with $\mathrm{Fe}_{3} \mathrm{O}_{4}$ nanoparticles had no side effects on plant growth and development [75]. Similarly, our results verified the previous research by observing the enhancement in growth parameters of tomato plants treated with various concentrations of IONPs.

\section{Impact of IONPs on disease attributes of tomato wilt}

Virulence of many pathogens relies on iron procurement so; occasionally microbial infections can be avoided by using iron-chelating products that inhibit pathogen's ability to approach iron [76]. Pot bioassays were performed to evaluate whether IONPs, considered as an agricultural antifungal agent, have potential to control Fusarium wilt disease (Fig. 10D,E). As shown in Figure S8A,B treating infected tomato seedlings with IONPs reduced the severity and incidence of Fusarium wilt caused by $F$. oxysporum. Furthermore, a clear positive correlation exists between the concentrations of NPs and disease-index. The disease in control plants were specifically severe after 25 days of post inoculation, and the disease severity came up to $96.67 \%$, however the disease severity of tomato seedlings exposed to IONPs at concentrations of $10,12.5$ and $15 \mu \mathrm{g} / \mathrm{mL}$ were reduced to $47.78 \%, 43.33 \%$ and $45 \%$ respectively. Though, with fungicide treatment a decline of $55 \%$ in disease severity was achieved (Figure S8A). The corresponding disease incidence in IONPs treated plants was $46.6 \%, 33.3 \%$ and $46.7 \%$ in 
contrast to the $100 \%$ control (Figure. S8B). Plants activate a toxic oxidative-burst by increasing iron levels to minimize pathogen virulence; roots mutualistic interactions also encounter phyto-diseases via iron uptake as well as competition for iron acquisition induces a systemic resistance that signal components in roots for iron-uptake [77]. There has no work been done so far on the application of iron oxide nanoparticles to combat plant diseases under field conditions, so recent work is considered as novel, and the results clearly indicates that these NPs has potential to become a part of disease management.

\section{Impact of IONPs on photosynthetic pigments}

The impacts of IONPs on the photosynthetic pigments were also accessed in this study by comparing diseased plants with treated ones (Figure S9A,B). Plant stress can also be indicated by changes in photosynthetic pigments [78]. Results indicated that various treatments of IONPs induces an increase in photosynthetic pigments. After exposure to $12.5 \mu \mathrm{g} / \mathrm{mL}$ IONPs, total chlorophyll and carotenoid contents in treated plants were significantly increased by $75.6 \%$ and $70.3 \%$ respectively in comparison to the control however, lower doses $(0.01$ and $0.5 \mu \mathrm{g} / \mathrm{mL}$ ) showed decline up to $27.7 \%$ and $1.94 \%$ for chlorophyll content and 19.05 and $8.54 \%$ for carotenoid content respectively. Askary et al. reported the similar results with application of nano-iron fertilizer [9]. Compared to the control, increased pigment production was detected for fungicide treatment, with an elevation of $56.1 \%$ and $55.1 \%(p<0.001)$ respectively. Iron plays a vital role in synthesis of chlorophyll; iron chlorosis reduces the level of photosynthetic pigments in plants effected the process of photosynthesis, while Fe-chlorosis is more frequent in photosystem-II analogous to photosystem-I [9]. The results demonstrated that higher doses of IONPs enhanced the synthesis of photosynthetic pigments in diseased plants by reducing chlorosis.

\section{Impact of IONPs on phenolic content and antioxidant enzymatic activities}

Plants endures stress environment by generating higher quantities of antioxidant enzymes, which enhances tolerance against oxidative burst [13]. Figure 11, 12: Figure S10 shows the phenolic content and activities of antioxidant enzymes (SOD, CAT, APX, GPX and POD) in the roots and shoots of diseased tomato plants in the presence of $0.01-15 \mu \mathrm{g} / \mathrm{mL}$ IONPs. Defensive response in plant induced as outcome of biotic-stress commonly involved phenolic-compounds [79]. The total phenolic content in roots and shoots of tomato plants significantly increased with increasing concentration of IONPs (Fig. 11A). In comparison to the control, total phenolic content in plants treated with $12.5 \mu \mathrm{g} / \mathrm{mL}$ of IONPs, showed an upsurge of 3.04 and 2.96-folds in roots and shoots respectively. In fungicide treatment the fold in roots and shoots increased up to1.96 and 1.89 respectively. Avio et al. reported increased phenolic content in lettuce, infected with Rhizoglomus irregulare positively associated with activities of antioxidant enzymes [80]. Increased phenolic compounds were detected in Molvadian balm under salinity stress after application of iron oxide nanoparticles [81]. Nourozi et al. demonstrated that iron oxide nanoparticles act as abiotic elicitor in Dracocephalum kotschyi enhancing accumulation of phenolic compounds [82].

SOD, a metalloenzyme, plays a key role in plant defence system by mobilizing the disproportionation of free-hydroxyl-radicals $\left(\mathrm{O}_{2}{ }^{--}\right)$to $\mathrm{H}_{2} \mathrm{O}_{2}$ to mediate ROS-toxicity [83]. SOD activity significantly enhanced in 
roots and shoots of infected tomato plants exposed to IONPs in parallel to the control treatment. The maximum activity, both in roots and shoots was recorded at $12.5 \mu \mathrm{g} / \mathrm{mL}$, which showed 3.11 and 2.79folds higher than the control treatment, whereas its activity dropped 0.39 and 0.42 times at $15 \mu \mathrm{g} / \mathrm{mL}$ compared with the control (Fig. 11B). Rui et al. observed increased SOD activity in peanut plant after treatment with iron-oxide nanoparticles in comparison to control and Fe-EDTA-treatment [84]. Interaction of iron-oxide nanoparticles and stress environment (salinity) enhances the activity of SOD enzyme; as iron is responsible for higher production of SOD; leads towards oxidative stress [82], therefore scavenging activity of some other antioxidant-enzymes such as POD, APX and CAT reduced the level of $\mathrm{H}_{2} \mathrm{O}_{2}$ in order to improve plants immunity against ROS burst [85]. Hence, lesser SOD activity at highest concentration of IONPs may induce reduction in ROS scavenging that ultimately increased mutilation in plants [86].

In plants, cellular destruction is being prevented by CAT involves in regulating $\mathrm{H}_{2} \mathrm{O}_{2}$ status in tissues by causing disintegration into oxygen and water molecules [87]. The CAT activity presented a dosedependent effect, higher concentration of IONPs indicates greater enzymatic activity both in roots and shoots (Fig. 11C). The CAT activity in tomato plants at various concentrations of IONPs revealed a fold increase of 1-3.21 in roots and 1.2-2.7 in shoots respectively as compared to the control $(p<0.05)$. Additionally, it can be assumed that higher activities of CAT interrelated with greater production of $\mathrm{H}_{2} \mathrm{O}_{2}$ and SOD activities [13]. APX consumes ascorbate and GPX employs glutathione as an electron-donor to downgrade ROS levels [88]. The activities of APX and GPX were significantly enhanced after application of IONPs both in roots and shoots. In plants treated with $12.5 \mu \mathrm{g} / \mathrm{mL}$ of IONPs, both root and shoot showed APX activity up to 1.98 and 2.03 times higher than the control (Fig. 12A). Similar trend was observed for GPX activity that gradually increased with doses of IONPs, surpassing the control by $71.8 \%$ and $73.7 \%$ at $12.5 \mu \mathrm{g} / \mathrm{mL}$ in root and shoots respectively (Figure. 12B). Both APX and GPX activities showed decline at $15 \mu \mathrm{g} / \mathrm{mL}$ Peroxidases is another defence related enzyme utilizes pyrogallol and guaiacol for detoxification of $\mathrm{H}_{2} \mathrm{O}_{2}$, involved in activating plant resistance against invading pathogen and wound healing [87]. A significant elevation was observed for POD activity in roots and shoots after exposure to IONPs. In comparison to the control the peroxidase activity, enhanced by 2.09, 2.13 and 2.05folds in roots and 2, 2.02 and 1.9-fold in shoots at $10,12.5$ and $15 \mu \mathrm{g} / \mathrm{mL}$ respectively (Fig. 12C). However, in all enzymatic activities fungicide treatment also indicates significant increase in comparison to the control treatment. Enzymes such as CAT, APX and POD containing iron-group participating in plantmetabolism by neutralizing hydrogen peroxide [89]. In agreement with the current work, earlier studies also reported the increase in secondary-metabolites and antioxidant enzymatic activities after treatment with iron-oxide nanoparticles in Citrus-maxima plant [90], Hyoscyamus reticulatus [91], Dracocephalum kotschyi [82], Oenothera biennis [92] and Dracocephalum moldavica [81] respectively.

\section{Impact of IONPs on growth and non-enzymatic compounds of tomato fruit}

Fruit quality is imperative for merchandise, pulpy fruits are putrescible, certain biotic and abiotic agents are intricating in deteriorating the quality of product [93]. Table 1 indicates substantial improvement in fruit variables (average weight and number) and non-enzymatic compounds of tomato fruit exposed to 
various concentrations of IONPs (Fig. 10F,G). The average fruit weight was significantly increased by $48.8 \%$ in presence of $12.5 \mu \mathrm{g} / \mathrm{mL}$ IONPs in comparison to the control. Similarly, the same trend was noted for fungicide treatment surpassing the control by $46.2 \%$ respectively. Likewise, under the same concentration $(12.5 \mu \mathrm{g} / \mathrm{mL})$ highest number of fruits, 32.6 per plant was counted with an increase of $51.6 \%$ respectively. Kumar et al. reported increases in fruit mass and fruit number per plant in strawberry after combined application of iron oxide and zinc oxide nanoparticles [94]. Furthermore, HernandezHernandez et al. observed $25 \%$ increase in tomato fruit weight after application of selenium and copper NPs [95].

Table 1: Average weight, number, antioxidant compounds and protein content in tomato fruits treated with IONPs

\begin{tabular}{|c|c|c|c|c|c|c|}
\hline Treatments & $\begin{array}{l}\text { Average Fruit } \\
\text { Weight } \\
\text { (g) }\end{array}$ & $\begin{array}{l}\text { Fruits } \\
\text { Number }\end{array}$ & $\begin{array}{l}\text { Lycopene } \\
\text { (mg } 100 \mathrm{~g}^{-} \\
{ }^{1} \mathrm{FW} \text { ) }\end{array}$ & $\begin{array}{l}\text { Flavonoids } \\
\text { (mg } 100 \mathrm{~g}^{-} \\
\left.{ }^{1} \mathrm{FW}\right)\end{array}$ & $\begin{array}{l}\text { Vitamin C } \\
\left(\mathrm{mg} 100 \mathrm{~g}^{-1}\right. \\
\text { FW) }\end{array}$ & $\begin{array}{l}\text { Protein } \\
\left(\mathrm{Umin}^{-1}\right. \\
\left.\mathrm{mg}^{-1}\right)\end{array}$ \\
\hline Control & 59.61 & 21.53 & 2.16 & 14.12 & 15.82 & 5.26 \\
\hline Fungicide & $87.19^{\star \star \star}$ & $30.12^{\star \star \star}$ & $3.42^{\star \star}$ & $20.42^{\star \star \star}$ & $17.42^{*}$ & $8.92^{\star \star \star}$ \\
\hline $\begin{array}{l}0.01 \mu \mathrm{g} / \mathrm{mL}- \\
\text { IONPs }\end{array}$ & $37.71^{\star \star \star}$ & $16.89^{\star \star \star}$ & 1.84 & 13.92 & $14.29^{*}$ & 4.75 \\
\hline $\begin{array}{l}0.5 \mu \mathrm{g} / \mathrm{mL}- \\
\text { IONPs }\end{array}$ & $42.29^{\star \star \star}$ & $18.67^{\star \star \star}$ & 1.98 & 14.19 & 14.75 & 4.86 \\
\hline $\begin{array}{l}1.5 \mu \mathrm{g} / \mathrm{mL}- \\
\text { IONPs }\end{array}$ & 57.81 & 20.53 & 2.06 & 15.25 & 15.37 & 5.12 \\
\hline $\begin{array}{l}2.5 \mu \mathrm{g} / \mathrm{mL}- \\
\text { IONPs }\end{array}$ & $69.63^{\star \star \star}$ & 21.84 & 2.49 & $16.52^{\star \star \star}$ & 16.21 & 5.67 \\
\hline $\begin{array}{l}5 \mu \mathrm{g} / \mathrm{mL}- \\
\text { IONPs }\end{array}$ & $74.64^{\star \star \star}$ & $23.74^{\star \star *}$ & 2.87 & $18.83^{\star \star \star}$ & 16.64 & $6.74^{\star *}$ \\
\hline 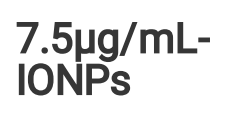 & $79.93^{* \star *}$ & $25.52^{\star \star \star}$ & 3.15 & $19.42^{\star \star \star}$ & 17.07 & $8.49^{\star \star \star}$ \\
\hline $\begin{array}{l}10 \mu \mathrm{g} / \mathrm{mL}- \\
\text { IONPS }\end{array}$ & $83.59^{\star \star \star}$ & $28.59^{\star \star \star}$ & $3.66^{\star \star \star}$ & $20.76^{\star \star \star}$ & $17.86^{\star * \star}$ & $8.74^{\star \star \star}$ \\
\hline $\begin{array}{l}\text { 12.5 } \mathrm{\mu g} / \mathrm{mL}- \\
\text { IONPs }\end{array}$ & $88.75^{\star \star \star}$ & $32.63^{\star \star \star}$ & $3.95^{\star \star \star}$ & $21.37^{\star \star \star}$ & $18.12^{\star \star \star}$ & $9.15^{\star \star \star}$ \\
\hline $\begin{array}{l}15 \mu \mathrm{g} / \mathrm{mL}- \\
\text { IONPS }\end{array}$ & $84.26^{\star \star \star}$ & $31.09^{\star \star \star}$ & $3.78^{\star \star \star}$ & $21.03^{\star \star \star}$ & $18.02^{\star \star \star}$ & $8.96^{\star \star \star}$ \\
\hline
\end{tabular}

Significant-difference $(* P<0.05 ; * * P<0.01 ; * \star * P<0.001)$ between different concentrations of IONPS and control group performed by one-way-ANOVA at $\mathrm{P}<0.05$ and Tukey-multiple-comparisons analysis. 
Tomato fruit has carotenoids such as lycopene, is one of the potent antioxidants, counteracts the ROS; another faction of lycopene in plants is associated with chemo- and photo protection [28, 96-97]. The lycopene content of tomato fruit significantly increased at $10,12.5$ and $15 \mu \mathrm{g} / \mathrm{mL}$ of IONPs, with an increase of $69.4 \%, 82.8 \%$ and $75 \%$ respectively in contrast to the control. Lower treatment (0.01-1.5 $\mu \mathrm{g} / \mathrm{mL}$ ) in comparison to the control showed non-significant decrease of $14.8 \%, 8.33 \%$ and $4.62 \%$ respectively. Some former studies specified that soil and foliar treatment of $\mathrm{TiO}_{2}, \mathrm{ZnO}$ and $\mathrm{CuO}$ nanoparticles enhanced lycopene content in tomato plants [98-99]. Foliar application of various treatments of copper nanoparticles significantly increased the lycopene content from $56.8 \%-105.3 \%$ in comparison to the control in tomato [100].

Flavonoids are the naturally available phyto-chemicals present in vegetables and fruits; having anti cancerous properties, acts as antioxidants to regulate ROS homeostasis [101]. The flavonoid-content in tomato fruit presented statistically substantial difference among treatments. The maximum flavonoidcontent was observed at $12.5 \mu \mathrm{g} / \mathrm{mL}$ generated a surge of $51.3 \%$ in relative to the control. Similarly, application of fungicide exceeding the control by $44.6 \%$. Nanoparticles induced the generation and accumulation of antioxidants like flavonoids, Vitamin C, carotenoids in plants as natural response against plant pathogens [102]. Regarding the vitamin $C$ content, there was $9.67 \%-2.84 \%$ decrease when lower treatment $(0.01-1.5 \mu \mathrm{g} / \mathrm{mL})$ of IONPs were applied. While three highest doses of IONPs (10$15 \mu \mathrm{g} / \mathrm{mL}$ ) including fungicide significantly increased the vitamin $C$ content in tomato fruit by $12.9 \%$, $14.5 \%, 13.9 \%$ and $10.1 \%$ with respect to the control. Vitamin C is most vital component of tomato fruit, signifies a key role by avoiding oxidative-damage [96]. Quiterio-Gutiérrez et al. reported increase in flavonoid and Vitamin C content in tomato fruit after application of selenium and copper nanoparticles [102]. Proteins has a key role in fruit growth and quality, tomato ripening is associated with function of regulatory proteins involved in initiation of ethylene- biosynthesis [103-104]. Total protein content significantly increased at the highest concentrations of IONPs in comparison to the control, reaching up to $28.1 \%, 61.4 \%, 66.2 \%, 73.9 \%$ and $70.3 \%$ with $5-15 \mu \mathrm{g} / \mathrm{mL}$ of IONPs respectively, the value also increased by $69.6 \%$ for fungicide treatment. However, the rest of the treatments didn't show significant difference from the control. Zaho et al. noticed increased protein content in cucumber fruit after application of nanoparticles [105].

\section{Conclusion}

Exploiting green-synthesized iron oxide nanoparticle, it was demonstrated that these nanoscale materials have a potential to become a part of diseases management system. Iron oxide nanoparticles (IONPs) nanoparticles were synthesized by mean of green approach using spinach as a starting material and black coffee as reducing / stabilizing agent. Microwave powers were varied form $100 \mathrm{~W}-1000 \mathrm{~W}$ in order to tune the properties of resulting product. XRD results showed cubic magnetite $\left(\mathrm{Fe}_{3} \mathrm{O}_{4}\right)$ phase of nanoparticles having superparamagnetic nature for all of the microwave powers. X-ray Photoelectron spectroscopy (XPS) results also confirmed the binding energies of Fe 2p3/2 (712.05 eV) and Fe 2p1/2 $(723.9 \mathrm{eV})$ of $\mathrm{Fe}_{3} \mathrm{O}_{4} \mathrm{NPs}$ synthesized using microwave power of $1000 \mathrm{~W}$. FTIR analysis confirmed the 
presence of cubic magnetite $\left(\mathrm{Fe}_{3} \mathrm{O}_{4}\right)$ phase for all of the microwave powers. Iron oxide nanoparticles extorted a strong antifungal activity against $F$. oxysporum at highest treatments. Exposure to IONPs not only inhibited fungal growth under in-vitro test, but also manages the Fusarium wilt of Tomato in pot bioassay. ROS generation, mycelium deformation and DNA fragmentation are due to interaction among nanoparticles and fungal cells could be related to intrinsic mechanism of the iron-oxide nanoparticles. Biosynthesized IONPs positively affects plant growth parameters and fruit quality by reducing the disease index. These findings clearly indicate that these nanomaterials have potential to repressed phytofungal-pathogens and paved a new pathway for nanoparticles to be used in agriculture in eco-friendly way.

\section{Abbreviations}

IONPs: Iron oxide nanoparticles; ROS: Reactive oxygen species; XRD: X-Ray Diffractometer; FTIR: Fourier Transform Infra-red spectroscopy; VSM: Vibrating sample magnetometer; XPS: X-ray Photoelectron spectroscopy; SEM: Scanning electron microscope; TEM: Transmission electron microscope; DI: Deionized water (DI); PDA: Potato dextrose agar; BC: Black coffee; $\mathrm{H}_{2}$ DCFDA: Dichloro-dihydrofluorescein-diacetate; PBS: Phosphate buffer saline; PI: Propidium iodide; DI: Disease incidence (DI); CAT: Catalase; SOD: Superoxide-dismutase; POD: Peroxidase; APX: Ascorbate-peroxidase; GPX: Glutathioneperoxidase

\section{Declarations}

\section{Availability of data and materials}

All data generated or analyzed in this study are included in this published article and its supplementary file.

\section{Acknowledgements}

Hina Ashraf is grateful to Higher Education Commission (HEC), Pakistan, for providing IRSIP (International Research Support Initiative program) Scholarship for conducting research at University of Illinois at Urbana Champaign in 2019 for six months. Authors are also thankful to HEC for providing research grant to the Centre of Excellence in Solid State Physics in year 2018-19.

\section{Funding}

Not applicable. The study was financially supported by authors and University of the Punjab, Lahore, Pakistan.

\section{Authors Contributions}

TA and SR designed the research, HA and TB analyzed the data and wrote the manuscript; HA performed in-vitro and in-vivo assays to detect the application of IONPs; TB performed synthesis and physico- 
chemical characterization of IONPs; SN and IA have revised the manuscript by providing technical guidance for various analyses. All the authors read and approved the final version of the manuscript.

\section{Ethic declarations}

\section{Ethics approval and consent to participate}

Not applicable

\section{Consent for publication}

All the authors agree with the publication.

\section{Competing Interest}

The authors declare no competing interests.

\section{Authors Information}

${ }^{1}$ Department of Plant Pathology, Faculty of Agricultural-Sciences, University of the Punjab, Lahore, Pakistan. ${ }^{2}$ Centre of Excellence in Solid-State-Physics, University of the Punjab, Lahore, Pakistan. ${ }^{3}$ Department of Agricultural \& Biological Engineering, University of Illinois at UrbanaChampaign, IL, USA. ${ }^{4}$ Holonyak Micro and Nanotechnology Laboratory, University of Illinois at UrbanaChampaign, IL, USA.

\section{References}

1. Shang Y, Hasan, MK, Ahammed, GJ, Li M, Yin H, Zhou J. Applications of Nanotechnology in Plant Growth and Crop Protection; A Review. Molecules (Basel, Switzerland). 2019;24: 2558.

2. Sandeep S, Bharat S, Pulkit B, Periyasamy P, Neeraj D, Ansuman S, Alok A, Vijayakumar S. TripleSmart Eco-Friendly Chili Anthracnose Control Agro-Nanocarrier. ACS Appl Mater Interfaces. 2021;13: 9143-9155.

3. Sidhu A, Bala A, Singh H, Ahuja R, Kumar, A. Development of MgO-Sepoilite Nanocomposites against Phytopathogenic Fungi of Rice (Oryzae sativa): A green Approach. ACS omega. 2020; 5: 1355713565.

4. Moradbeygi H, Jamei R, Heidari R, Darvishzadeh R. Investigating the Enzymatic and Non-Enzymatic Antioxidant Defense by Applying Iron Oxide Nanoparticles in Dracocephalum Moldavica L. Plant Under Salinity Stress. Sci Hortic. 2020; 272: 109537.

5. Fu L, Wang Z, Dhankher OP, Xing B. Nanotechnology as a New Sustainable Approach for Controlling Crop Diseases and Increasing Agricultural Production. J Exp Bot. 2020; 71:507-519.

6. Vasantharaj S, Sathiyavimal S, Senthilkumar P, Oscar FL, Pugazhendhi A. Biosynthesis of Iron Oxide Nanoparticles using Leaf Extract of Ruellia tuberosa: Antimicrobial properties and their Applications 
in Photocatalytic Degradation. J Photochem Photobiol B: Biol. 2019; 192: 74-84.

7. Kah M, Tufenkji N, White JC. Nano-enabled Strategies to Enhance Crop Nutrition and Protection. Nat Nanotechnol. 2019;14:532-540

8. Babajani A, Iranbakhsh A, Oraghi AZ, Eslami B. Differential growth, Nutrition, Physiology, and Gene expression in Melissa officinalis Mediated by Zinc oxide and Elemental Selenium Nanoparticles. Environ Sci Pollut Res. 2019; 26: 24430-24444.

9. Askary M, Amirjani MR, Saberi T. Comparison of the effects of Nano-Iron Fertilizer with Iron-Chelate on Growth Parameters and some Biochemical properties of Catharanthus roseus. J Plant Nutr. 2017;40: 974-982.

10. Rahmatizadeh R, Arvin SMJ, Jamei R, Mozaffari H, Nejhad FR. Response of Tomato plants to Interaction effects of Magnetic $\left(\mathrm{Fe}_{3} \mathrm{O}_{4}\right)$ Nanoparticles and Cadmium Stress. J. Plant Interact. 2019; 14:474-481.

11. Moradi S, Khaledian S, Abdoli M, Shahlaei M, Kahrizi D. Nano-biosensors in Cellular and Molecular Biology. Cell. Mol. Biol. (Noisy-le-grand). 2018;64:85-90.

12. Tripathi DK, Singh S, Gaur S, Yadav V, Liu S, Singh V, Sharma S, Srivastava P, Prasad S, Dubey N, Chauhan DK, Sahi S. Acquisition and Homeostasis of Iron in Higher plants and their Probable Role in Abiotic Stress Tolerance. Front Environ Sci. $2018 ; 5: 86$.

13. Chahardoli A, Karimi N, Ma X, Qalekhani F. Effects of Engineered Aluminum and Nickel Oxide Nanoparticles on the Growth and Antioxidant Defense systems of Nigella arvensis L. Sci Rep. 2020; 10: 3847.

14. Rizwan M, Ali S, Ali B, Adrees M, Arshad M, Hussain A, Rehman MZ, Waris AA. Zinc and Iron oxide Nanoparticles Improved the Plant Growth and Reduced the Oxidative Stress and Cadmium Concentration in Wheat. Chemosphere. 2018; 214; 269-277.

15. Babaei K, Seyed SR, Pirzad A, Khalilzadeh R. Effects of Bio fertilizer and Nano Zn-Fe oxide on Physiological Traits, Antioxidant Enzymes Activity and Yield of Wheat (Triticum aestivum L.) under Salinity stress. J Plant Interact. 2017; 12: 381-389.

16. Akbar A, Hussain S, Ullah K, Fahim M, Ali GS. Detection, Virulence and Genetic Diversity of Fusarium species Infecting Tomato in Northern Pakistan. PLoS One. 2018; 13: e0203613.

17. Adisa IO, Pullagurala VLR, Rawat S, Hernandez-Viezcas JA, Dimkpa CO, Elmer WH, White JC, PeraltaVidea JR, Gardea-Torresdey JL. Role of Cerium compounds in Fusarium Wilt Suppression and Growth Enhancement in Tomato (Solanum lycopersicum). J Agric Food Chem. 2018; 66: 59595970.

18. Servin A, Elmer W, Mukherjee A, Torre-Roche R, Hamdi H, White JC, Bindraban P, Dimkpa C. A review of the use of Engineered Nanomaterials to Suppress Plant Disease and Enhance Crop Yield. J Nanopart Res. 2015;17: 1-21.

19. Alam T, Akbar F, Ali M, Munis MFH, Khan J. Biosynthesis of Iron oxide Nanoparticles via Crocus sativus and their Antifungal Efficacy against Verticillium wilt Pathogen Verticillium dahlia. BioRxiv. 2019; 861401. 
20. Kokina I, Plaksenkova I, Jermallonoka M, Petrova, A. Impact of Iron oxide Nanoparticles on Yellow Medick (Medicago falcata L.) Plants. J Plant Interact. 2020; 15: 1-7.

21. Azhdari S, Sarabi R, Rezaeizade N, Mosazade F, Heidari MJ, Borhani F, Abdollahpour-Alitappeh M, Khatami M. Metallic SPIONP/AgNP synthesis using a Novel Natural source and their Antifungal Activities. RSC Adv. 2020;10: 29737-29744.

22. Saqib S, Zaman W, Ullah F, Majeed I, Ayaz A, Hussain-Munis MF. Organometallic Assembling of Chitosan-Iron oxide Nanoparticles with their Antifungal Evaluation against Rhizopus oryzae. Appl Organometal Chem. 2019; 33: e5190.

23. Parveen S, Wani A, Shah MA, Devi HS, Bhat MY, Koka JA. Preparation, Characterization and Antifungal activity of Iron oxide Nanoparticles. Microb Pathol. 2018; 115: 287-292.

24. Koka JA, Wani AH, Bhat MY. Evaluation of Antifungal activity of Magnesium oxide ( $\mathrm{MgO})$ and Iron oxide (FeO) Nanoparticles on Rot causing Fungi. J Drug Deliv Ther. 2019;9:173-178.

25. Zhao RT, Kong W, Sun MX, Yang Y, Liu WY, Lv M, Song S, Wang L, Song H, Hao R. Highly stable Graphene-based Nanocomposite (GO-PEI-Ag) with Broad-spectrum, Long-term Antimicrobial activity and Antibiofilm effects. ACS Appl Mater Interfaces. 2018;10: 17617-17629.

26. Chen J, Wu L, Lu M, Lu S, Li Z, Ding W. Comparative Study on the Fungicidal Activity of Metallic MgO Nanoparticles and Macroscale MgO against Soilborne Fungal Phytopathogens. Front Microbiol. 2020: $11 ; 365$.

27. Arakha M, Pal S, Samantarrai D, Panigrahi TK, Mallick BC, Pramanik K, Mallick B, Jha S. Antimicrobial activity of Iron Oxide nanoparticle upon modulation of nanoparticle-bacteria interface. Sci Rep. 2015; 5: 14813.

28. Klunklin W, Savage G. Effect on Quality Characteristics of Tomatoes Grown Under Well-Watered and Drought Stress Conditions. Foods (Basel, Switzerland) 2017; 6: 56.

29. Al-Shabib NA, Husain FM, Ahmed F, Khan RA, Khan MS, Ansari FA, Alam MZ, Ahmed MA, Khan MS, Baig MH, Khan JM, Shahzad SA, Arshad M, Alyousef A, Ahmad I. Low Temperature Synthesis of Superparamagnetic Iron Oxide $\left(\mathrm{Fe}_{3} \mathrm{O}_{4}\right)$ Nanoparticles and Their ROS Mediated Inhibition of Biofilm Formed by Food-Associated Bacteria. Front Microbiol. 2018; 9 : 2567.

30. Sharma A, Rajendran S, Srivastava A, Sharma S, Kundu B. Antifungal Activities of Selected Essential Oils against Fusarium oxysporum f. sp. lycopersici 1322, with Emphasis on Syzygium aromaticum Essential Oil. J Biosci Bioeng. 2017; 123: 308-313.

31. Rossi FR, Krapp AR, Bisaro F, Maiale SJ, Pieckenstain FL, Carrillo N. Reactive Oxygen Species Generated in Chloroplasts Contribute to Tobacco Leaf Infection by the Necrotrophic Fungus Botrytis cinerea. Plant J. 2017;92: 761-773.

32. Wei J, Bi Y, Xue H, Wang Y, Zong Y, Prusky D. Antifungal Activity of Cinnamaldehyde against Fusarium sambucinum Involves Inhibition of Ergosterol Biosynthesis. J Appl Microbiol. 2020;129: 256-265. 
33. Ashraf H, Anjum T, Riaz S, Naseem S. Microwave-Assisted Green Synthesis and Characterization of Silver Nanoparticles using Melia azedarach for the Management of Fusarium Wilt in Tomato. Front Microbiol. 2020; 11:238.

34. Popoola AR, Durosomo AH, Afolabi CG, Idehen E. Regeneration of Somaclonal Variants of Tomato (Solanum lycopersicum L.) for Resistance to Fusarium Wilt. J Crop Improv. 2015;29: 636 - 649.

35. Herrera-Becerra R, Rius JL, Zorrilla C. (2010). Tannin Biosynthesis of Iron Oxide Nanoparticles. Appl Phys A. 2010;100: 453-459.

36. Tan GQ, Zheng YQ, Miao HY, Xia A, Ren HJ. Controllable Microwave Hydrothermal synthesis of Bismuth Ferrites and Photocatalytic Characterization. J Am Ceram Soc. 2012; 95: 280-289.

37. Cullity BD. Elements of X-ray Diffraction. Addison-Wesley Publishing, New York, USA,1956; pp 490505.

38. Barsoukov E. Macdonald J.R. (eds). Impedance Spectroscopy: Theory, Experiment, and Applications. $2^{\text {nd }}$ ed. John Wiley \& Sons. Hoboken, New Jersey, 2005; pp 1-583.

39. Ni S, Lin S, Pan Q, Yang F, Huang K, He D. Hydrothermal synthesis and microwave absorption properties of $\mathrm{Fe}_{3} \mathrm{O}_{4}$ nanocrystals. J Phys D: Appl Phys. 2009;42: 055004.

40. Nithya VD, Selvan RK. Synthesis, electrical and dielectric properties of $\mathrm{FeVO}_{4}$ nanoparticles. Phys B: Condens Matter. 2011;406:24-29.

41. Ali T, Ahmed A, Tripathi P. Enhanced dielectric properties of Fe-substituted $\mathrm{TiO}_{2}$ nanoparticles. Phys B: Condens Matter. 2018; 534: 1-4.

42. Panda RK, Muduli R, Kar SK, Behera D. Dielectric Relaxation and Conduction Mechanism of Cobalt Ferrite Nanoparticles. J Alloys Compd. 2014;615: 899-905.

43. Shah ZH, Riaz S, Atiq S, Naseem S. Tunable Structural and Electrical Impedance Properties of Ordered and Disordered Iron Oxide Phases for Capacitive Applications. Ceram Int. 2018; 44: 1635216364.

44. Raees K, Ansari MS, Rafiquee MZA. Inhibitive Effect of Super Paramagnetic Iron Oxide Nanoparticles on the Alkaline Hydrolysis of Procaine. J Nanostructure Chem. 2019: 175-187.

45. Sanaullah I, Bukhari BS, Batool T, Riaz S, Khan HN, Sabri AN, Naseem S. Antibacterial Performance of Glucose-Fructose added MW Based Zirconia Coatings-Possible Treatment for Bone Infection. J Mech Behav Biomed Mater. 2020;104: 103621.

46. Manukyan KV, Chen YS, Rouvimov S, Li P, Li X, Dong S, Mukasyan AS. Ultrasmall a-Fe $\mathrm{O}_{2} \mathrm{O}_{3}$ Superparamagnetic Nanoparticles with High Magnetization Prepared by Template-Assisted Combustion Process. J Phys Chem C. 2014;118: 16264-16271.

47. Grosvenor AP, Kobe BA, Biesinger MC, Mclntyre NS. Investigation of Multiplet Splitting of Fe2p XPS Spectra and Bonding in Iron Compounds. Surf Interface Anal. 2004; 36: 1564-1574.

48. Tiwari S, Prakash R, Choudhary RJ, Phase DM. Oriented growth of $\mathrm{Fe}_{3} \mathrm{O}_{4}$ thin film on crystalline and amorphous substrates by pulsed laser deposition. J Phys D: Appl Phys. 2007; 40:4943-4947. 
49. Medina-Llamas M, Mattia D. Semi-continuous production of iron oxide nanoparticles via membrane emulsification. Appl Surf Sci. 2019;463: 504-512.

50. Nasrin Beheshtkhoo N, Kouhbanani MAJ, Savardashtaki A, Amani AM, Taghizadeh S. Green Synthesis of Iron Oxide Nanoparticles by Aqueous Leaf Extract of Daphne mezereum as a Novel Dye Removing Material. Appl Phys A. 2018; 124: 363.

51. Aivazoglou E, Metaxa E, Hristoforou E. Microwave-assisted synthesis of iron oxide nanoparticles in biocompatible organic environment. AIP Adv. 2018; 8: 048201.

52. Kostyukhin, EM, Nissenbaum VD, Abkhalimov EV, Kustov AL, Ershov BG, Kustov LM. MicrowaveAssisted Synthesis of Water-Dispersible Humate-Coated Magnetite Nanoparticles: Relation of Coating Process Parameters to the Properties of Nanoparticles. Nanomaterials. 2020; 10: 1558.

53. Lagashetty A, Ganiger S, Preeti R, Reddy S, Pari M. Microwave-Assisted Green Synthesis, Characterization and Adsorption Studies on Metal Oxide Nanoparticles Synthesized using Ficus benghalensis Plant Leaf Extracts. New J Chem. 2020; 44: 14095-14102.

54. Ramezani M, Ramezani F, Gerami M. Nanoparticles in Pest Incidences and Plant Disease Control. In: Panpatte, D.G.; Jhala, Y.K. (Eds.) Nanotechnology for Agriculture: Crop Production \& Protection. Springer Nature Singapore, 2019; pp 233-272.

55. Nehra P, Chauhan RP, Garg N, Verma K. Antibacterial and Antifungal Activity of Chitosan Coated Iron Oxide Nanoparticles. Br J Biomed Sci 2018; 75: 13-18.

56. Wang L, Hu C, Shao L. The Antimicrobial Activity of Nanoparticles: Present Situation and Prospects for the Future. Int J Nanomed. 2017;12:1227-1249.

57. Guo Q, Zhao Y, Dai X, Zhang T, Yu Y, Zhang X, Li C. Functional Silver Nanocomposites as BroadSpectrum Antimicrobial and Biofilm-Disrupting Agents. ACS Appl Mater Interfaces 2017; 9: 1683416847.

58. Devi HS, Boda MA, Shah MA, Parveen S, Wani AH. Green Synthesis of Iron Oxide Nanoparticles using Platanus orientalis Leaf Extract for Antifungal Activity. Green Process Synth. 2018; 8:38 - 45.

59. Salem DM, Ismail M, Aly-Eldeen MA. Biogenic Synthesis and Antimicrobial Potency of Iron Oxide $\left(\mathrm{Fe}_{3} \mathrm{O}_{4}\right)$ Nanoparticles using Algae Harvested from the Mediterranean Sea, Egypt. Egypt $J$ Aquat Res. 2019;45:197-204.

60. Arias LS, Pessan JP, Vieira A, Lima T, Delbem A, Monteiro DR. Iron Oxide Nanoparticles for Biomedical Applications: A Perspective on Synthesis, Drugs, Antimicrobial Activity, and Toxicity. Antibiotics (Basel, Switzerland), 2018;7:46.

61. Niemirowicz K, Durnaś B, Tokajuk G, Głuszek K, Wilczewska AZ, Misztalewska I, Mystkowska J, Michalak G, Sodo A, Wątek M, Kiziewicz B, Gozdz S, Gluszek S, Bucki R. Magnetic Nanoparticles as a Drug Delivery System that Enhance Fungicidal Activity of Polyene Antibiotics. Nanomedicine. 2016;12:2395-2404.

62. Wang L, Wu H, Qin G, Meng X. Chitosan Disrupts Penicillium expansum and Controls Postharvest Blue Mold of Jujube Fruit. Food Control. 2014;41:56-62. 
63. Hong SC, Lee JH, Lee J, Kim HY, Park JY, Cho J, Lee J, Han DW. Subtle Cytotoxicity and Genotoxicity Differences in Superparamagnetic Iron Oxide Nanoparticles Coated with Various Functional Groups. Int J Nanomed. 2011;6: 3219-3231.

64. Caldeirão ACM, Araujo HC, Tomasella CM, Sampaio C, dos Santos Oliveira MJ, Ramage G, Pessan JP, Monteiro DR. Effects of Antifungal Carriers Based on Chitosan-Coated Iron Oxide Nanoparticles on Microcosm Biofilms. Antibiotics. 2021;10:588.

65. Niemirowicz K, Durnaś B, Tokajuk G, Piktel E, Michalak G, Gu X, Kułakowska A, Savage PB, Bucki R. Formulation and Candidacidal activity of Magnetic Nanoparticles Coated with Cathelicidin LL-37 and Ceragenin CSA-13. Sci Rep. 2017;7:4610.

66. Hauser AK, Mitov MI, Daley EF, McGarry RC, Anderson KW, Hilt JZ. Targeted Iron Oxide Nanoparticles for the Enhancement of Radiation Therapy. Biomaterials. 2016; 105:127-135.

67. Kang B, Austin LA, El-Sayed MA. Observing Real-Time Molecular Event Dynamics of Apoptosis in Living Cancer Cells using Nuclear-Targeted Plasmonically Enhanced Raman Nanoprobes. ACS Nano. 2014; 8:4883-4892.

68. Alarifi S, Ali D, Alkahtani S, Alhader M.S. Iron Oxide Nanoparticles Induce Oxidative Stress, DNA Damage, and Caspase Activation in the Human Breast Cancer Cell Line. Biol Trace Elem Res. 2014; 159:416-424.

69. Plaksenkova I, Jermaḷonoka M, Bankovska L, Gavarāne I, Gerbreders V, Sledevskis E, Sniḳeris J, Kokina I. Effects of $\mathrm{Fe}_{3} \mathrm{O}_{4}$ Nanoparticle Stress on the Growth and Development of Rocket Eruca sativa. J Nanomater. 2019; 1-10.

70. Fecker R, Buda V, Alexa E, Avram S, Pavel IZ, Muntean D, Cocan I, Watz C, Minda D, Dehelean CA, Soica C, Danciu C. Phytochemical and Biological Screening of Oenothera Biennis L. Hydroalcoholic Extract. Biomolecules 2020;10:818.

71. Hussain A, Ali S, Rizwan M, Rehman M, Qayyum MF, Wang H, Rinklebe J. Responses of Wheat (Triticum Aestivum) Plants Grown in a Cd Contaminated Soil to The Application of Iron Oxide Nanoparticles. Ecotox. Environ Safe. 2019;173:156-164.

72. Sundaria N, Singh M, Upreti P, Chauhan RP, Jaiswal JP, Kumar A. Seed Priming with Iron Oxide Nanoparticles Triggers Iron Acquisition and Biofortification in Wheat (Triticum aestivum L.) Grains. J Plant Growth Regul. 2019; 38:122-131.

73. Li J, Chang PR, Huang J, Wang Y, Yuan H, Ren H. Physiological Effects of Magnetic Iron Oxide Nanoparticles Towards Watermelon. J Nanosci Nanotechnol. 2013;13:5561-5567.

74. Kasote DM, Lee JHJ, Jayaprakasha GK, Patil BS. Seed Priming with Iron Oxide Nanoparticles Modulate Antioxidant Potential and Defense-Linked Hormones in Watermelon Seedlings. ACS Sustain Chem Eng. 2019; 7:5142-5151.

75. Lau ECHT, Carvalho LB, Pereira AES, Montanha GS, Corrêa CG, Carvalho HWP, Ganin AY, Fraceto LF, Yiu HHP. Localization of Coated Iron Oxide $\left(\mathrm{Fe}_{3} \mathrm{O}_{4}\right)$ Nanoparticles on Tomato Seeds and Their Effects on Growth. ACS Appl Biomater. 2020;3:4109-4117. 
76. Kontoghiorghes GJ, Kolnagou A, Skiada A, Petrikkos G. The role of iron and chelators on infections in iron overload and non-iron loaded conditions: prospects for the design of new antimicrobial therapies. Hemoglobin. 2010;34: 227-239.

77. Verbon EH, Trapet PL, Stringlis IA, Kruijs S, Bakker PAHM, Pieterse CMJ. Iron and Immunity. Annu Rev Phytopathol. 2017;55:355-375.

78. Borgatta J, Ma C, Hudson-Smith N, Elmer W, Plaza Pérez, CD, De la Torre-Roche R, Zuverza-Mena N, Haynes CL, White JC, Hamers RJ. Copper Based Nanomaterials Suppress Root Fungal Disease in Watermelon (Citrullus lanatus): Role of Particle Morphology, Composition and Dissolution Behavior. ACS Sustain Chem Eng. 2018; 6:14847-14856.

79. Kumar D, Yusuf MA, Singh P, Sardar M, Sarin NB. Modulation of Antioxidant Machinery in ATocopherol-Enriched Transgenic Brassica Juncea Plants Tolerant to Abiotic Stress Conditions. Protoplasma. 2013;250:1079-1089.

80. Avio L, Sbrana C, Giovannetti MS, Frassinetti S. Arbuscular Mycorrhizal Fungi Affect Total Phenolics Content and Antioxidant Activity in Leaves of Oak Leaf Lettuce Varieties. Sci Hortic. 2017; 224:265271.

81. Moradbeygi $\mathrm{H}$, Jamei R, Heidari R, Darvishzadeh $\mathrm{R}$. $\mathrm{Fe}_{2} \mathrm{O}_{3} \mathrm{NPs}$ Induced Biochemical Responses and Expression of Genes Involved in Rosmarinic Acid Biosynthesis Pathway in Moldavian Balm Under Salinity Stress. Physiol Plant. $2020 ; 169$ : 555-570.

82. Nourozi E, Hosseini B, Maleki R, Abdollahi Mandoulakani B. Iron Oxide Nanoparticles : A Novel Elicitor to Enhance Anticancer Flavonoid Production and Gene Expression in Dracocephalum Kotschyi Hairy-Root Cultures. J Sci Food Agric. 2019;99:6418-6430.

83. Yang J, Weidong C, Rui Y. Interactions between Nanoparticles and Plants: Phytotoxicity and Defense Mechanisms. J Plant Interact. 2017; 12:158-169.

84. Rui M, Ma C, Hao Y, Guo J, Rui Y, Tang X, Zhao Q, Fan X, Zhang Z, Hou T, Zhu S. Iron Oxide Nanoparticles as a Potential Iron Fertilizer for Peanut (Arachis hypogaea). Front Plant Sci. 2016; 7: 815.

85. Ma C, Liu H, Guo H, Musante C, Coşkun SH, Nelson B, White J, Xing B, Dhankher OP. Defense Mechanisms and Nutrient Displacement in Arabidopsis thaliana Upon Exposure to $\mathrm{CeO}_{2}$ and $\ln _{2} \mathrm{O}_{3}$ Nanoparticles. Environ Sci Nano. 2016; 3:1369-1379.

86. Hatami M, Ghorbanpour M. Defense Enzyme Activities and Biochemical Variations of Pelargonium Zonale in Response to Nanosilver Application and Dark Storage. Turk J Biol. 2014; 38: 130-139.

87. Song G, Hou W, Gao Y, Wang Y, Lin L, Zhang Z, Niu Q, Ma R, Mu L, Wang H. Effects of CuO nanoparticles on Lemna minor. Bot Stud. 2016;57: 3.

88. Zhao L, Hu Q, Huang Y, Fulton AN, Hannah-Bick C, Adeleye A, Keller A. Activation of Antioxidant and Detoxification Gene Expression in Cucumber Plants Exposed to a $\mathrm{Cu}(\mathrm{OH})_{2}$ Nanopesticide. Environ Sci Nano. 2017; 4: 1750-1760. 
89. Anwar A, Yan Y, Liu Y, Li Y, Yu X. 5-Aminolevulinic Acid Improves Nutrient Uptake and Endogenous Hormone Accumulation, Enhancing Low-Temperature Stress Tolerance in Cucumbers. Int J Mol Sci. 2018; 19:3379.

90. Hu J, Guo H, Li J, Wang Y, Xiao L, Xing B. Interaction of $\mathrm{Y}-\mathrm{Fe}_{2} \mathrm{O}_{3}$ Nanoparticles with Citrus maxima Leaves and the Corresponding Physiological Effects via Foliar Application. J Nanobiotechnol. 2017; 15: 51 .

91. Moharrami F, Hosseini B, Sharafi A, Farjaminezhad M. Enhanced Production of Hyoscyamine and Scopolamine from Genetically Transformed Root Culture of Hyoscyamus reticulatus L. Elicited by Iron Oxide Nanoparticles. In Vitro Cell Dev Biol-Plant 2017; 53: 104-111.

92. Asadi-Kavan Z, Khavari-Nejad RA, Alireza Iranbakhsh A, Najafi F. Cooperative Effects of Iron Oxide Nanoparticle $\left(\mathrm{a}-\mathrm{Fe}_{2} \mathrm{O}_{3}\right)$ and Citrate on Germination and Oxidative System of Evening Primrose (Oenthera biennis L.), J Plant Interact. 2020; 15:166-179.

93. Yang T, Peng H, Whitaker BD, Jurick WM. Differential Expression of Calcium/Calmodulin Regulated Slsrs in Response to Abiotic and Biotic Stresses in Tomato Fruit. Physiol Plant. 2013; 148:445-455.

94. Kumar U, Bahadur V, Prasad V, Mishra S, Shukla P. Effect of Different Concentrations of Iron Oxide and Zinc Oxide Nanoparticles on Growth and Yield of Strawberry (Fragaria x ananassa Duch) cv. Chandler. Int J Curr Microbiol Appl Sci. 2017;6:2440-2445.

95. Hernández-Hernández H, Quiterio-Gutiérrez T, Cadenas-Pliego G, Ortega-Ortiz H, Hernández-Fuentes AD, Cabrera de la Fuente M, Valdés-Reyna J, Juárez-Maldonado, A. Impact of Selenium and Copper Nanoparticles on Yield, Antioxidant System, and Fruit Quality of Tomato Plants. Plants (Basel, Switzerland). 2019; 8: 355.

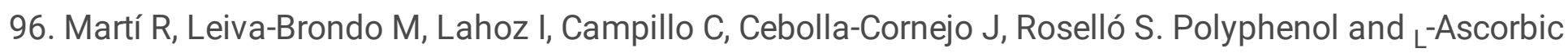
Acid Content in Tomato as Influenced by High Lycopene Genotypes and Organic Farming at Different Environments. Food Chem. 2018; 23:148-156.

97. Havaux M. Carotenoid Oxidation Products as Stress Signals in Plants. Plant J. 2014;79:597-606.

98. Raliya R, Nair R, Chavalmane S, Wang WN, Biswas P. Mechanistic Evaluation of Translocation and Physiological Impact of Titanium Dioxide and Zinc Oxide Nanoparticles on the Tomato (Solanum Lycopersicum L.) Plant Metallomics. 2015; 7:1584-1594.

99. Ashraf H, Anjum T, Riaz S, Ahmad I, Irudayaraj J, Javed S, Qaiser U, Naseem S. Inhibition Mechanism of Green-Synthesized Copper-Oxide Nanoparticles from Cassia fistula towards Fusarium oxysporum by Boosting Growth and Defense Responses in Tomatoes. Environ Sci Nano 2021; 8:1729-1748.

100. López-Vargas E, Ortega-Ortíz H, Cadenas-Pliego G, de Alba Romenus K, Cabrera de la Fuente M, Benavides-Mendoza A, Juárez-Maldonado A. Foliar Application of Copper Nanoparticles Increases the Fruit Quality and the Content of Bioactive Compounds in Tomatoes. Appl Sci. 2018; 8:1020.

101. González-Moscoso M, Martínez-Villegas NV, Cadenas-Pliego G, Benavides-Mendoza A, Rivera-Cruz M, González-Morales S, Juárez-Maldonado A. Impact of Silicon Nanoparticles on the Antioxidant Compounds of Tomato Fruits Stressed by Arsenic. Foods (Basel, Switzerland). 2019; 8: 612. 
102. Quiterio-Gutiérrez T, Ortega-Ortiz H, Cadenas-Pliego G, Hernández-Fuentes AD, Sandoval-Rangel A, Benavides-Mendoza A, Cabrera-de la Fuente M, Juárez-Maldonado A. The Application of Selenium and Copper Nanoparticles Modifies the Biochemical Responses of Tomato Plants under Stress by Alternaria solani. Int J Mol Sci. 2019;20:1950.

103. Cai J, Wang P, Tian S, Qin G. Quantitative Proteomic Analysis Reveals the Involvement of Mitochondrial Proteins in Tomato Fruit Ripening. Postharvest Biol Technol. 2018;145:213-221.

104. Szymanski J, Levin Y, Savidor A, Breitel D, Chappell-Maor L, Heinig U, Töpfer N, Aharoni A. Label-Free Deep Shotgun Proteomics Reveals Protein Dynamics During Tomato Fruit Tissues Development. Plant J. 2017;90:396-417.

105. Zhao L, Peralta-Videa JR, Rico CM, Hernandez-Viezcas JA, Sun Y, Niu G, Servin A, Nunez JE, DuarteGardea M, Gardea-Torresdey JL. CeO囚 and ZnO Nanoparticles Change the Nutritional Qualities of Cucumber (Cucumis sativus). J Agric Food Chem. 2014;62:2752-2759.

\section{Figures}

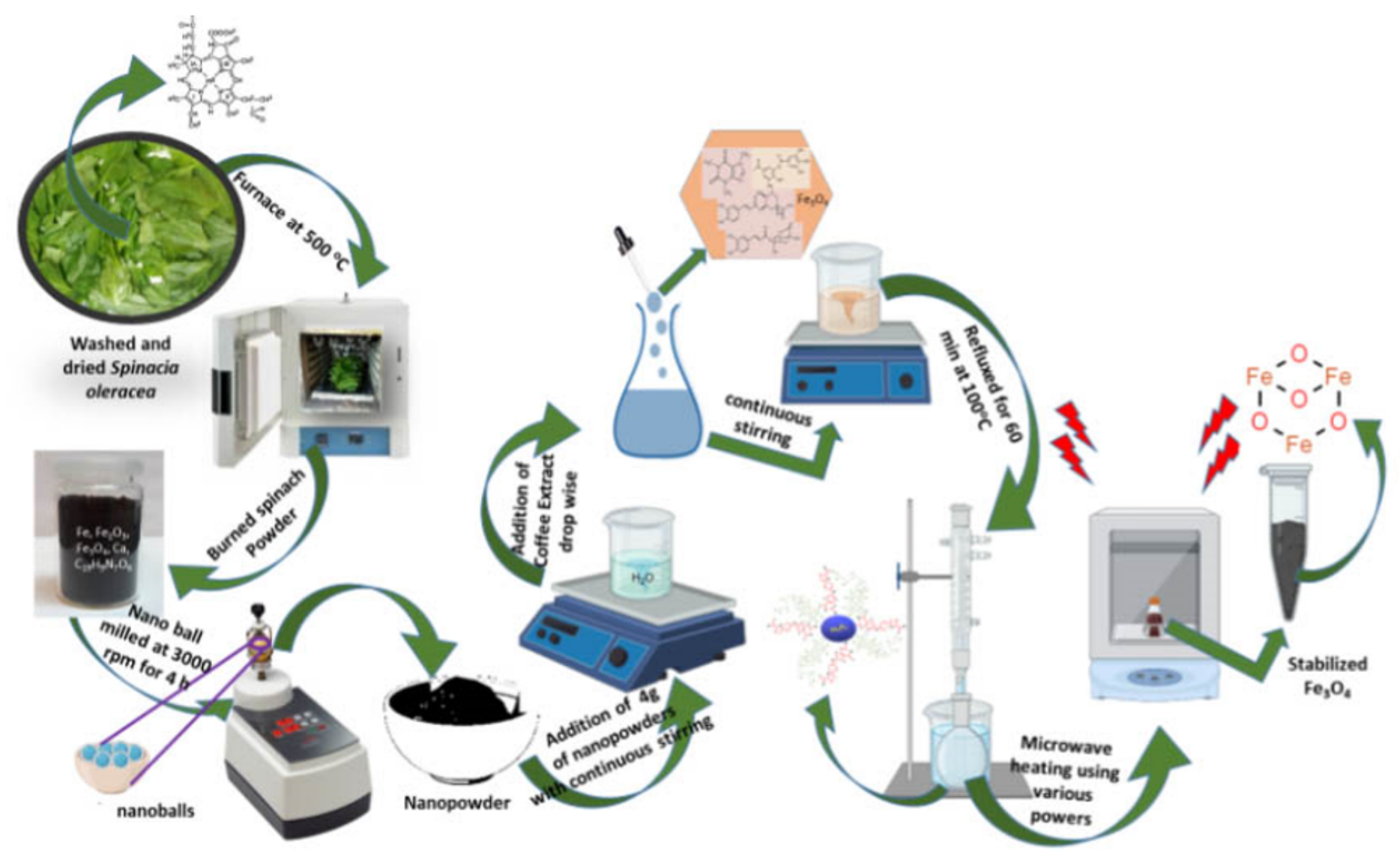

\section{Figure 1}

Schematic showing green synthesis of IONPs using spinach and black coffee extract by varying microwave powers (100 W- $1000 \mathrm{~W})$ 


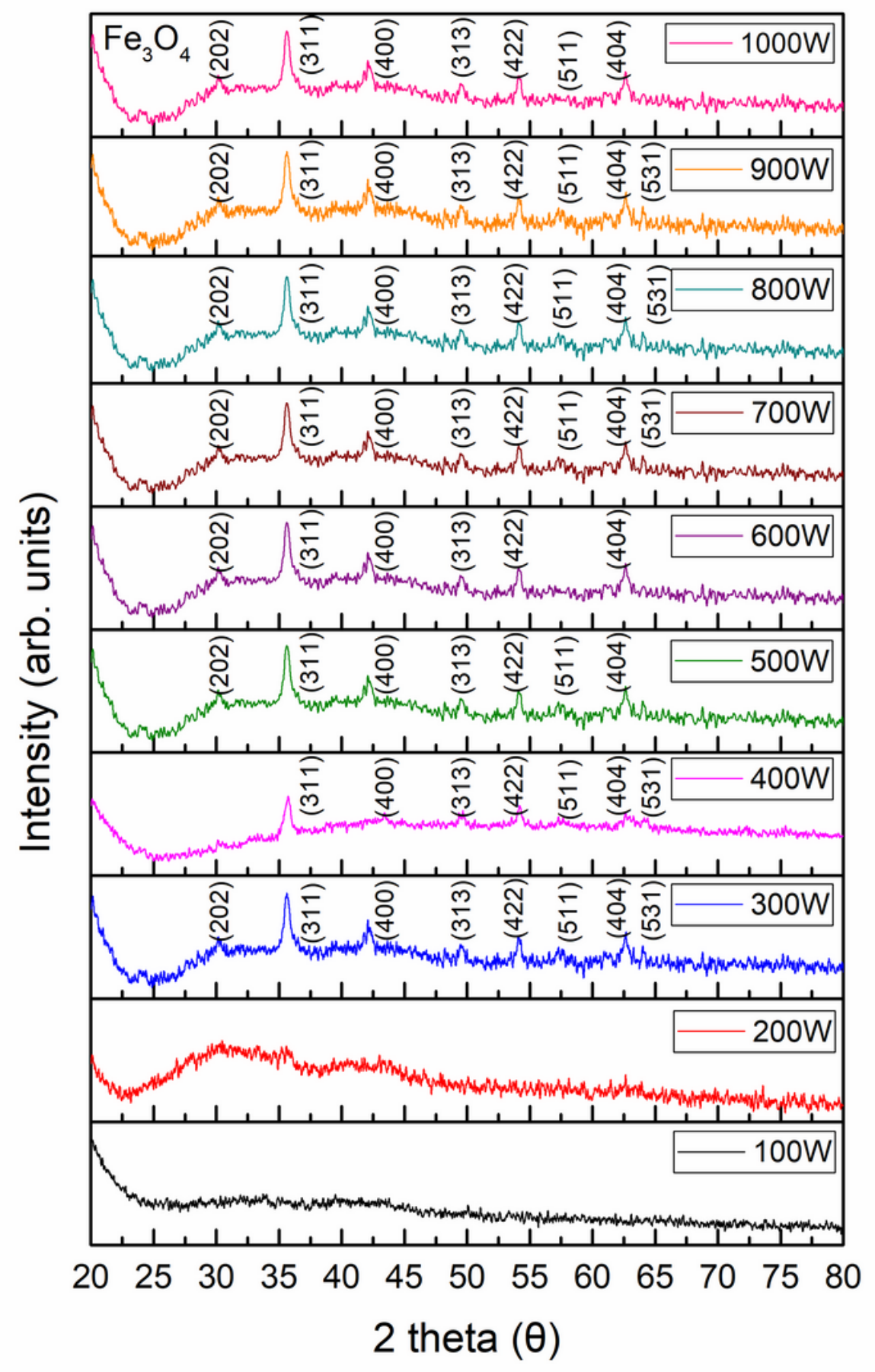

Figure 2

Structural analysis by X-ray diffraction: XRD spectra of IONPs synthesized by using spinach leaves and Black coffee (BC) extract, subjected to various microwave powers (100W-1000W) with CuKa (1.5406 A) radiations in the range of $2 \theta=20^{\circ}-80^{\circ}$ and an operating voltage of $40 \mathrm{kV}$ at $15 \mathrm{~mA}$. Peaks matched with standard XRD spectrum of Fe2O3 NPs as per JCPDS card no. 19-629. 

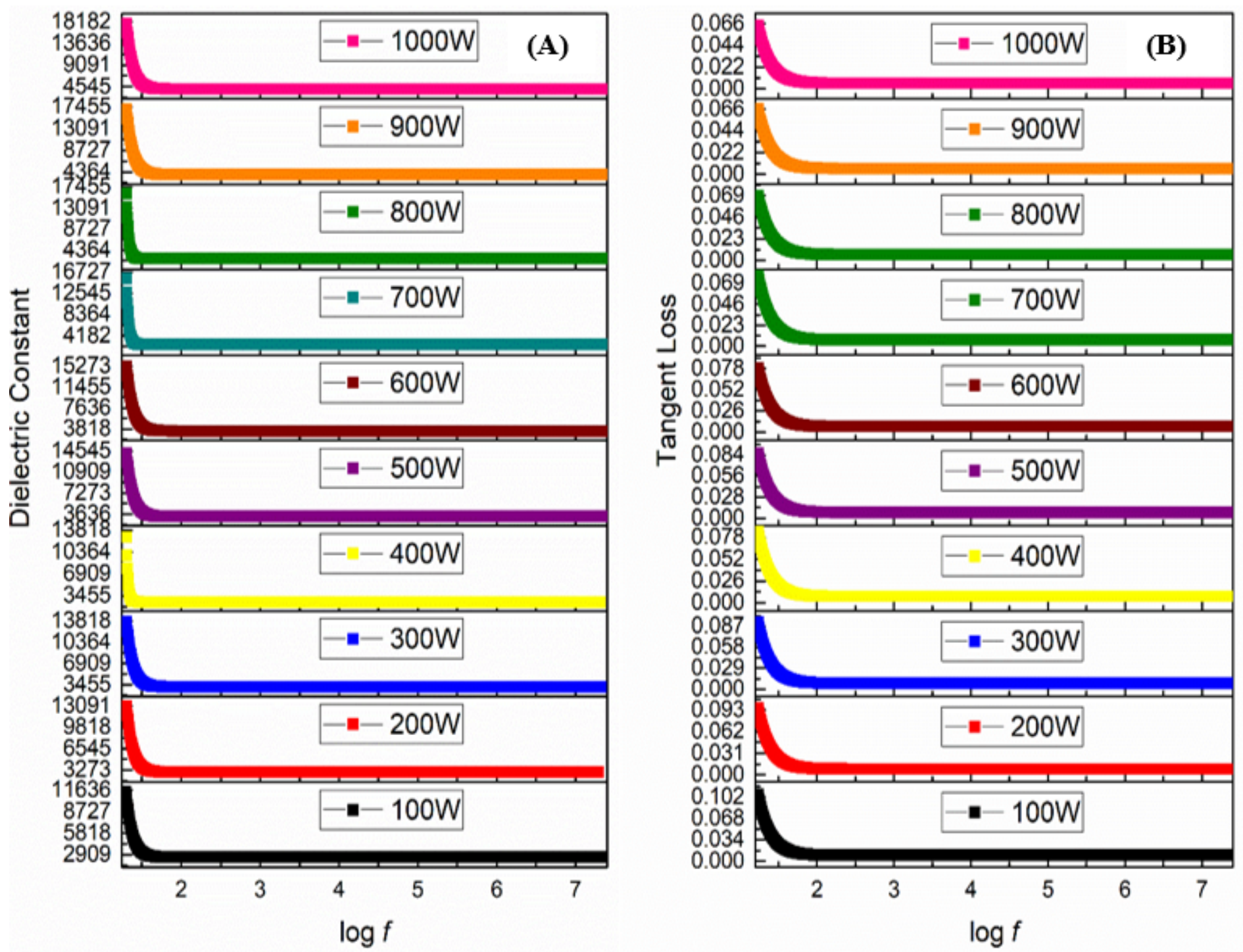

Figure 3

Dielectric analysis of green synthesized IONPs: Room temperature response of dielectric constant (a), tangent loss (b) at various microwave powers (100 W- $1000 \mathrm{~W}$ ). 

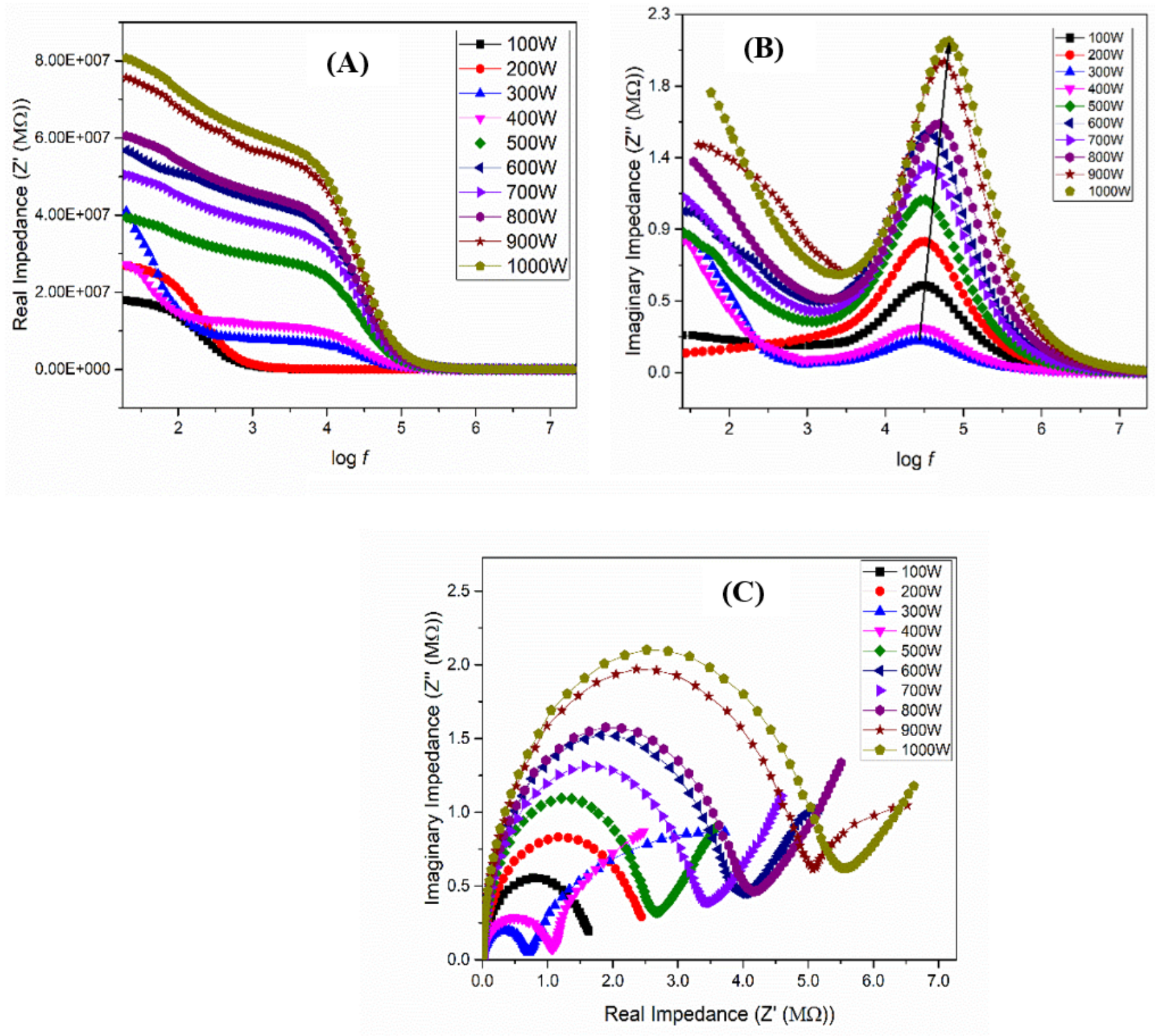

Figure 4

Impedance spectroscopic analysis: (a) Real impedance: (b) Imaginary impedance: (c) and Cole-Cole plots were drawn to extract information about electrical characteristics of green synthesized IONPs 

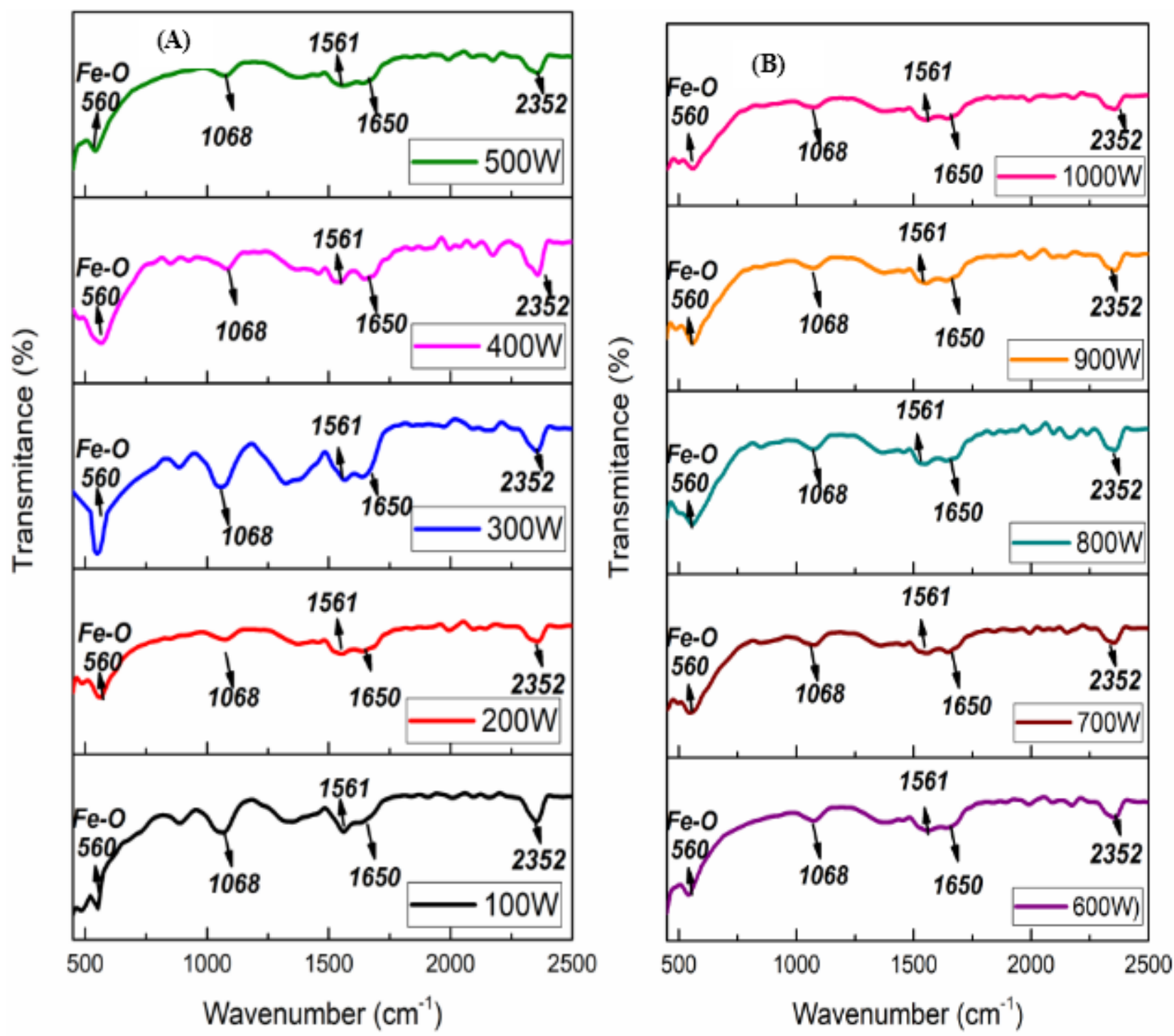

Figure 5

Fourier transform infrared (FTIR) spectroscopic analysis of IONPs: FTIR spectra for green synthesized iron oxide nanoparticles synthesized at various microwave powers by using spinach and black coffee extracts, (a) $100 \mathrm{~W}-500 \mathrm{~W}$; (b) $600 \mathrm{~W}-1000 \mathrm{~W}$ in a range of $500-2500 \mathrm{~cm}-1$ at $4 \mathrm{~cm}-1$ resolutions in diffuse-reflectance mode by using $\mathrm{KBr}$ (potassium bromide) pellets in the ratio of 1:100. 

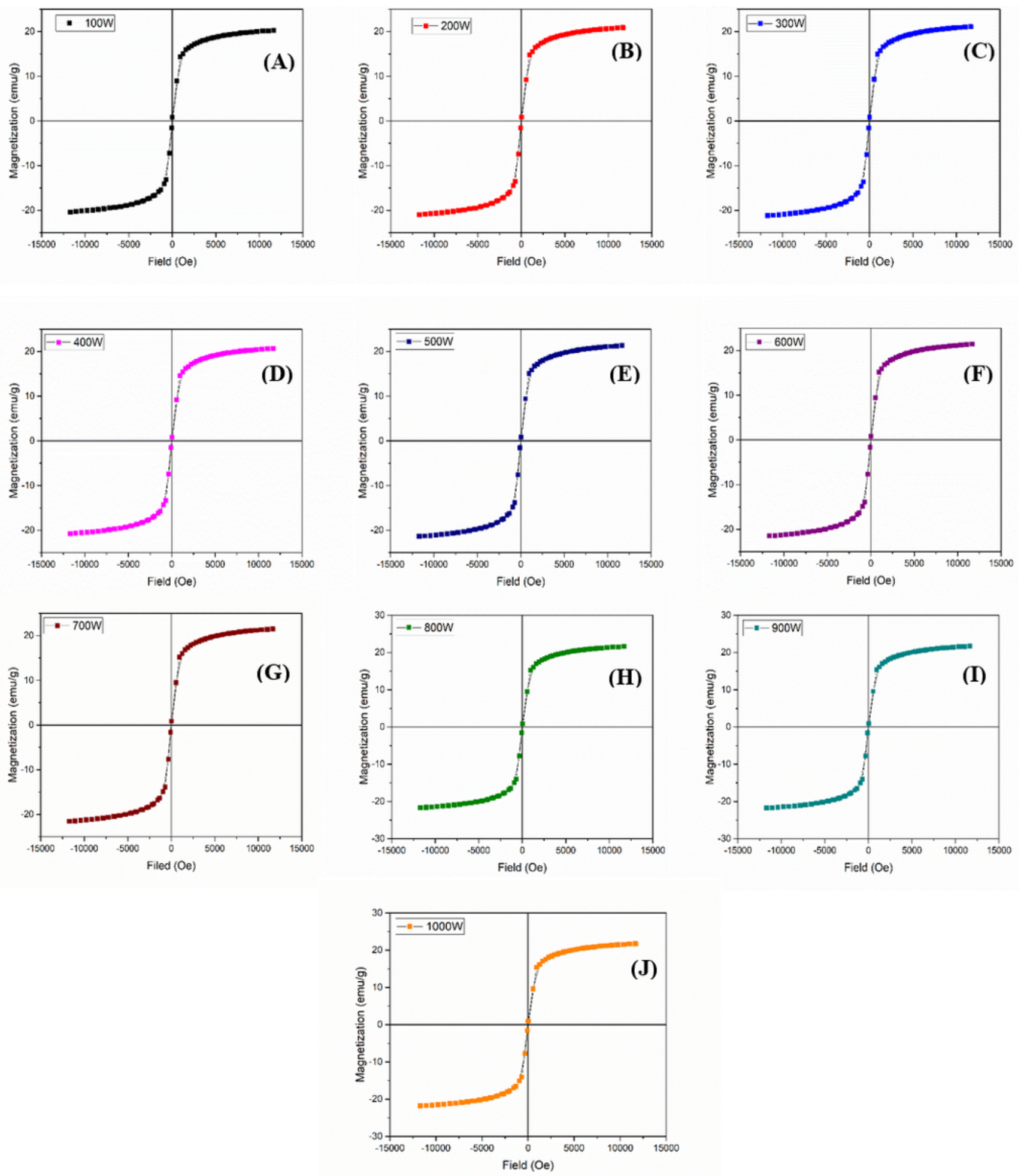

\section{Figure 6}

Superparamagnetic response of green synthesized IONPs: Magnetization curves (a-j) of IONPs obtained by Vibrating sample magnetometer (VSM), synthesized at various microwave powers (100 W- $1000 \mathrm{~W}$ ). Magnetization unit is represented by emu/g respectively. 

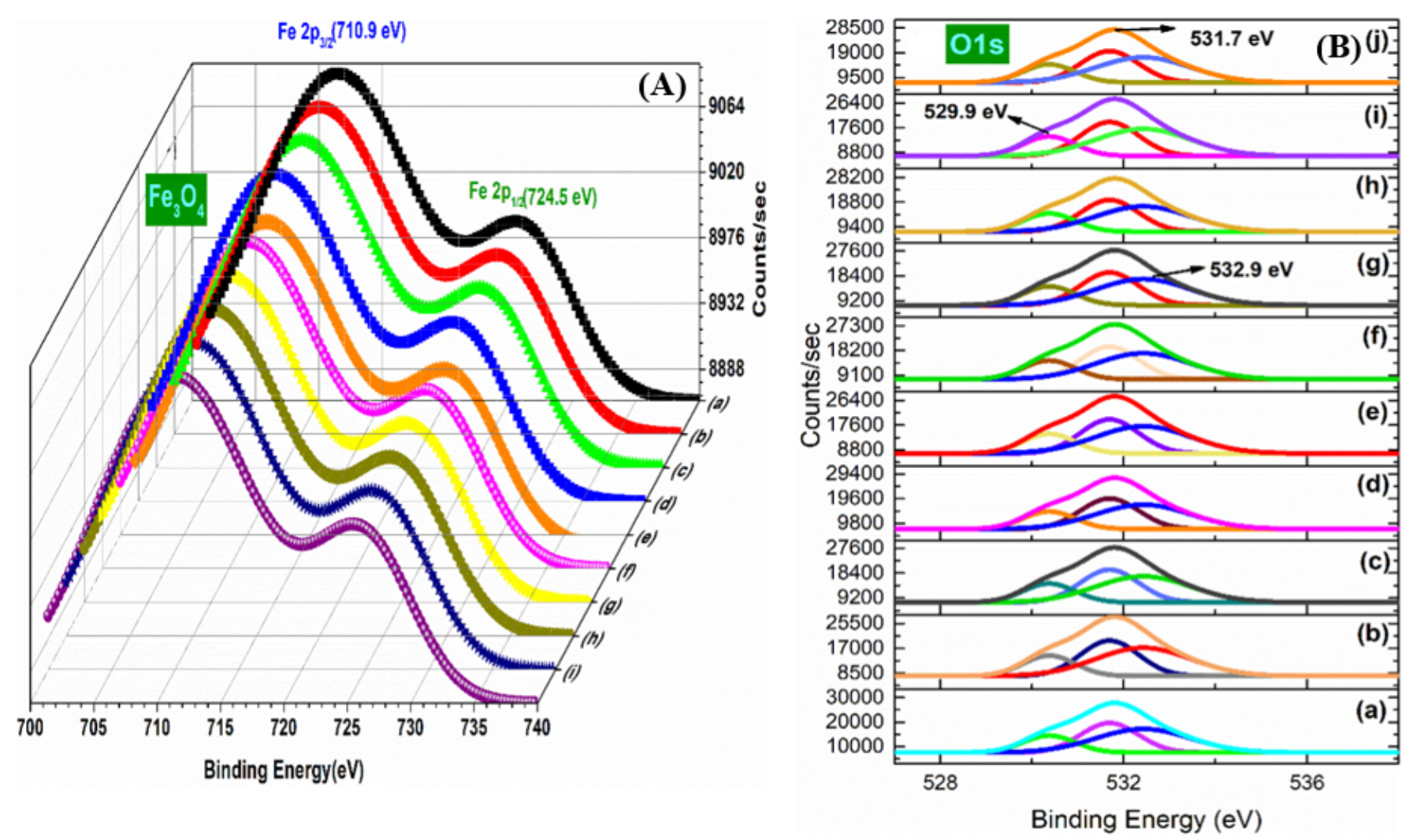

Figure 7

X-ray photoelectron Spectroscopic analysis of IONPs synthesized at various microwave powers (100 W1000 W: a-i): XPS spectra of (A) Fe2p and (B) 01s. 
(A)

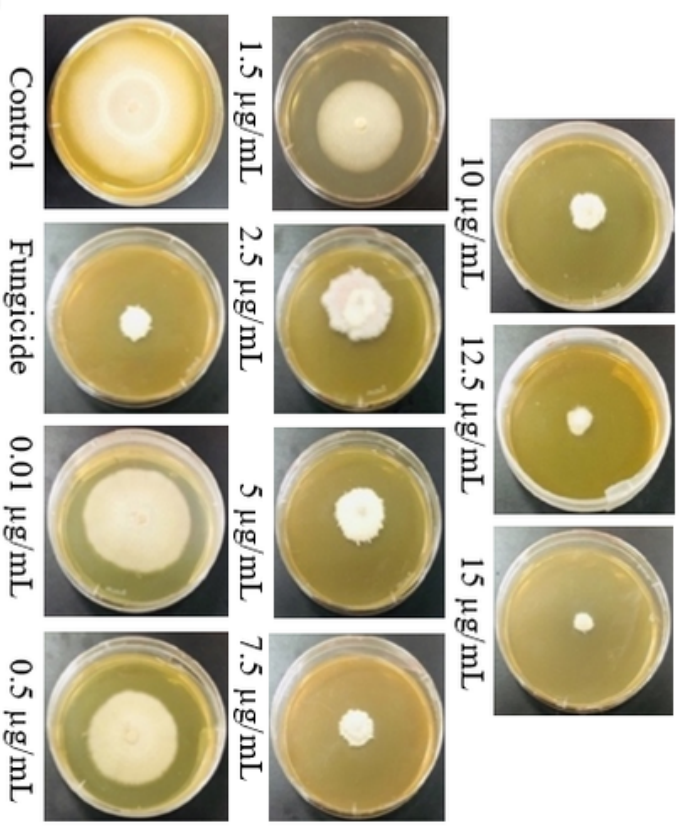

(C)

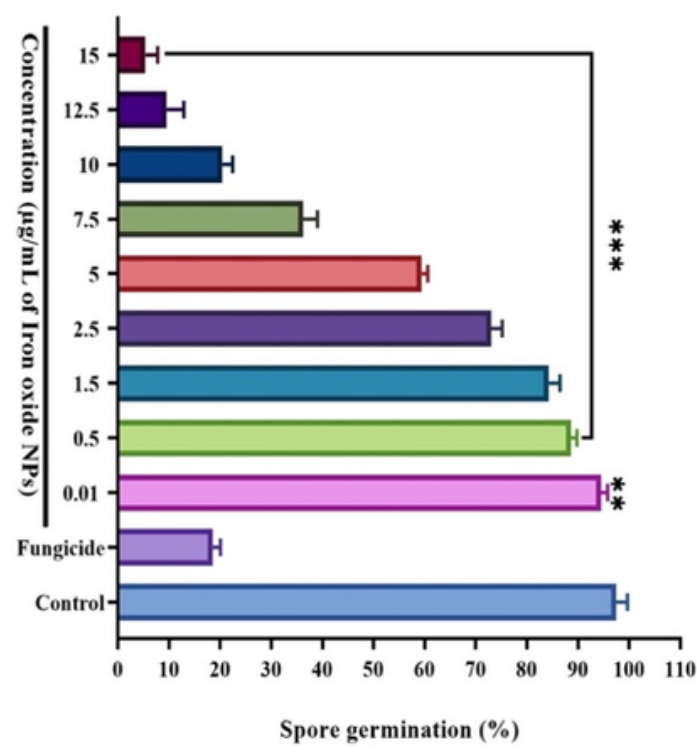

(B)

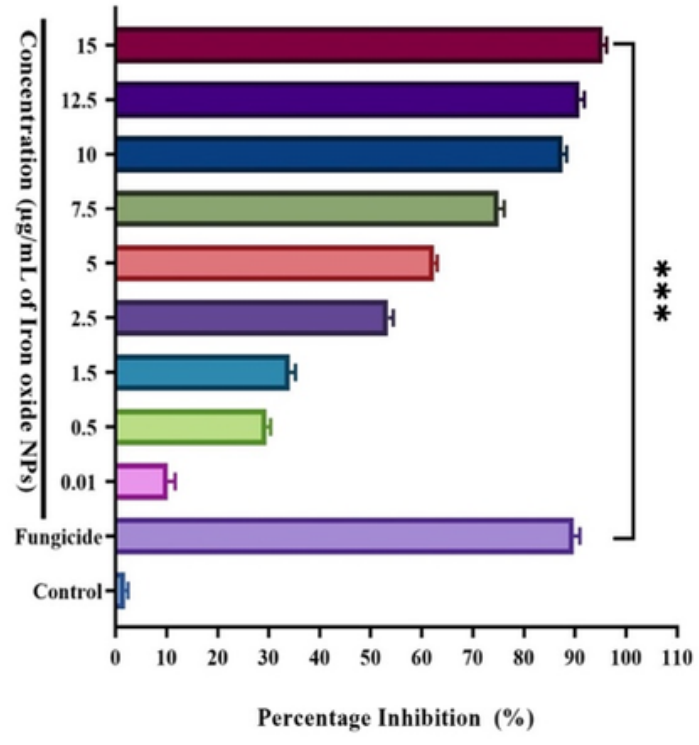

(D

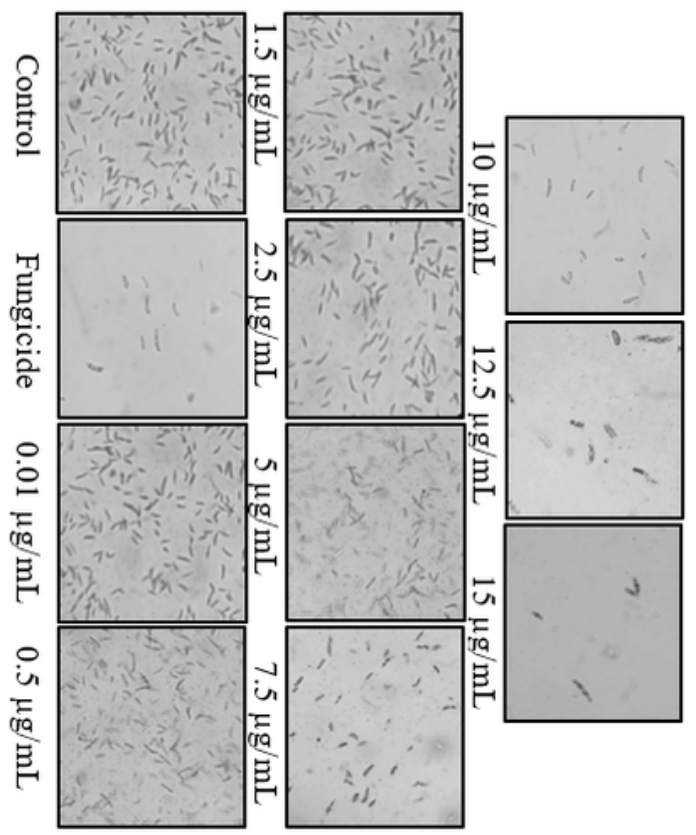

\section{Figure 8}

Comparing the effect of Iron-oxide nanoparticles (IONPs) on F. oxysporum mycelial radial-growth and spore-germination at various concentrations $(0.01-15 \mu \mathrm{g} / \mathrm{mL})$ in parallel to the control and fungicide treatment after seven days of post incubation at $28^{\circ} \mathrm{C}$. A: Showing percentage inhibition graph of IONPs on mycelial growth of F. oxysporum, B: plates indicating antifungal activity of nanoparticle on PDA plates. C: Represents percentage spore's germination, D: Indicating fungal spores germination rate treated 
with different concentrations of NPs viewed under light microscope (10x magnification). Data represents as a mean $\pm S D(n=3)$ of three replicates indicating significant-difference $\left({ }^{* *} p<0.01 ; * \star \star p<0.001\right)$ as compared to control by one-way-ANOVA $(P<0.05)$ and Tukey's-multiple comparing tests.
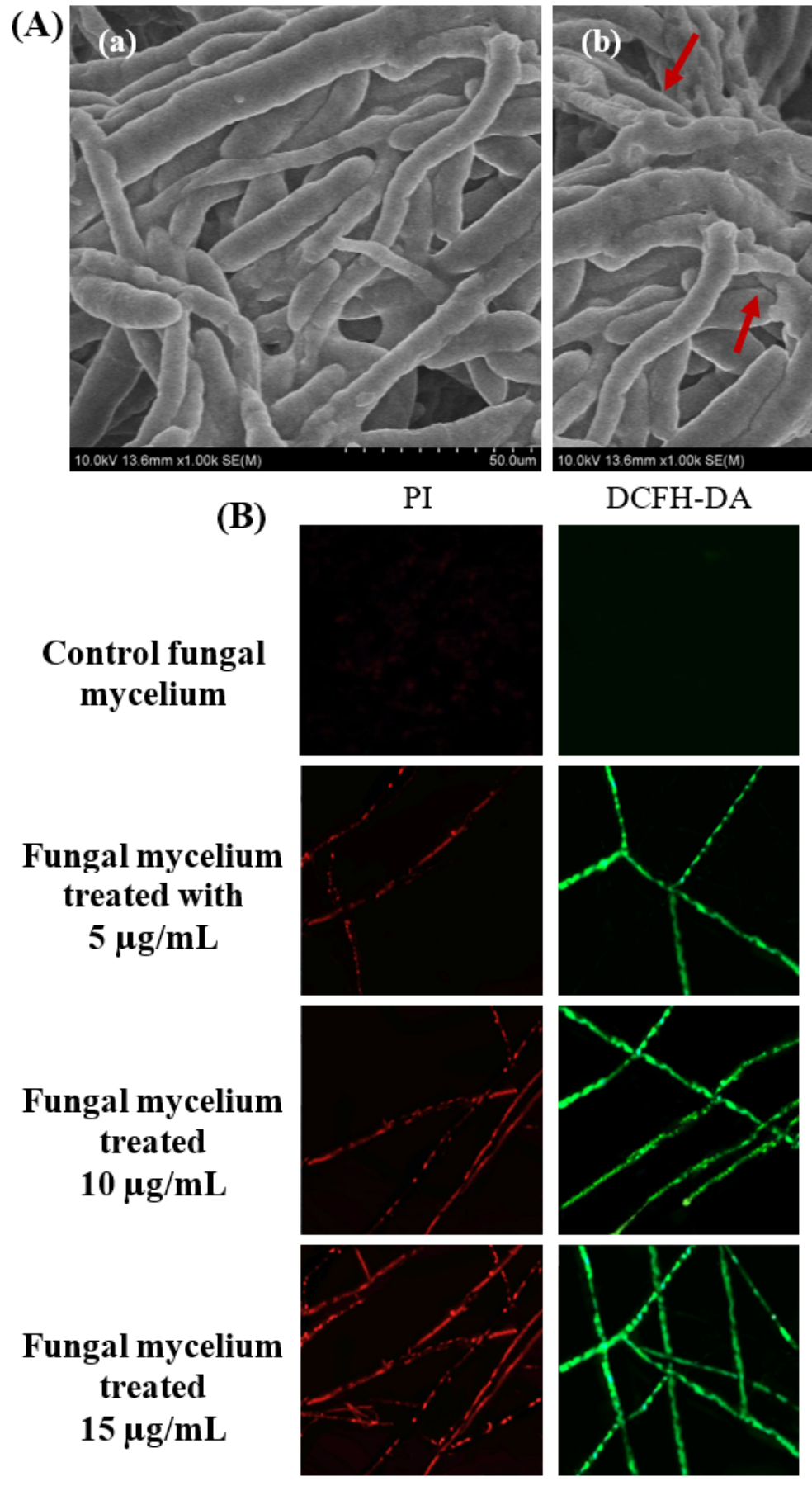

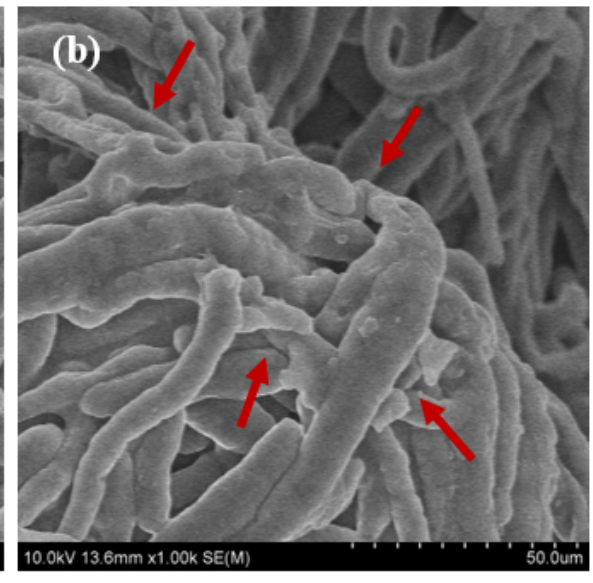

(C)
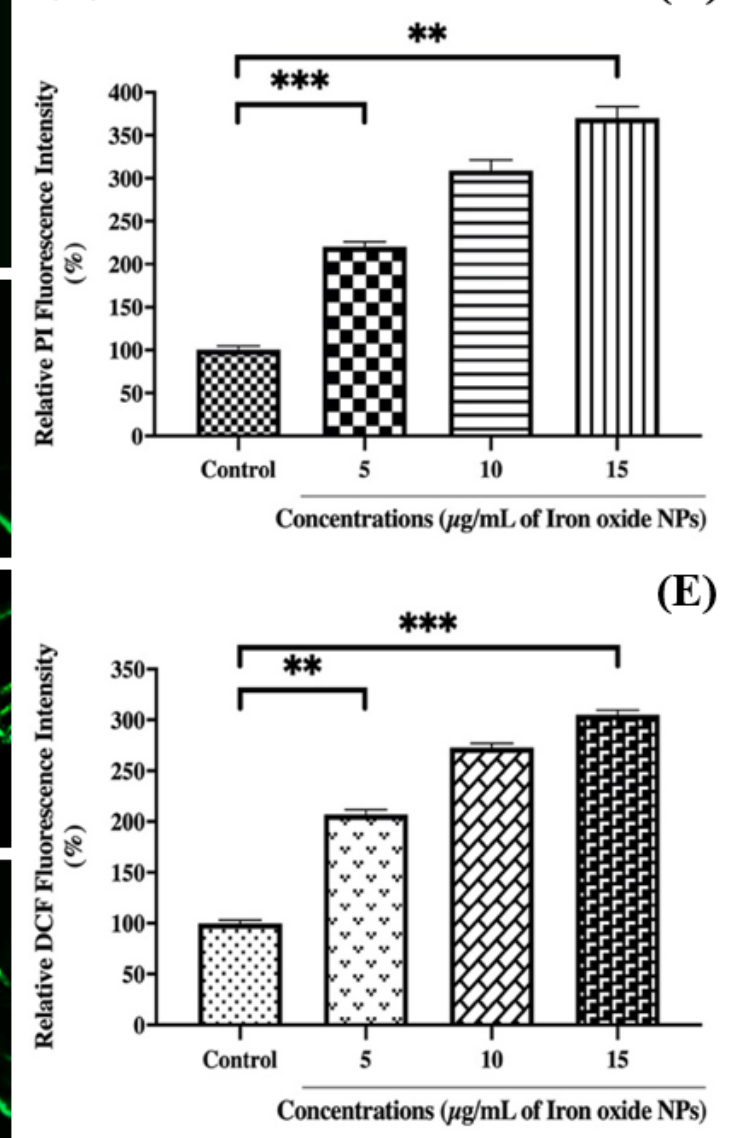

(E)

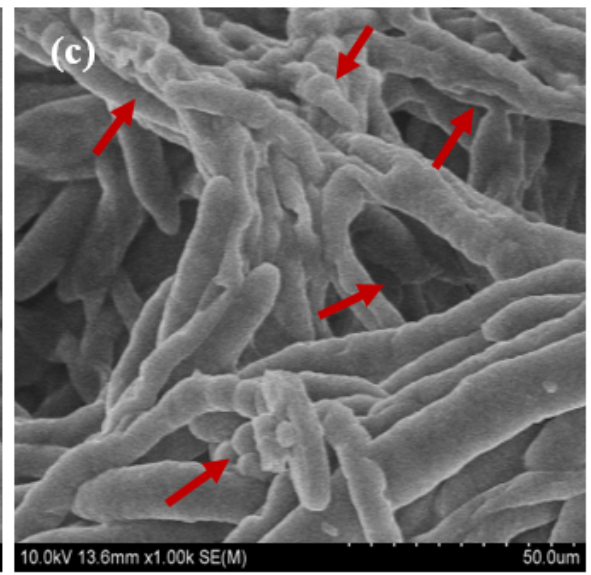

(D)

\section{Figure 9}

Assessing the effect of Iron-oxide nanoparticles on fungal morphology, intracellular reactive oxygen species (ROS) and membrane integrity. (A) Scanning-electron-microscope (SEM) micrographs of $F$. oxysporum hyphae treated with IONPs (a) sterilized-water (control), (b) $10 \mu \mathrm{g} / \mathrm{mL}$ and (c) $15 \mu \mathrm{g} / \mathrm{mL}$, (B \& C) showing red (RFP) and green (GFP) fluorescent protein micrographs of control and IONPs treated 
fungal hyphae, Scale bar: 10 $\mu \mathrm{m}$, (D \& E) representing fluorescent intensity of propidium iodide (PI) and dichloro-dihydro-fluorescein diacetate (DCFH-DA) in dose-dependent manner. Graph denotes significantdifference ( $\left.{ }^{\star *} P<0.01 ; * \star * P<0.001\right)$ in fluorescence-intensity between different concentrations of nanoparticle and control group performed by one-way-ANOVA at $\mathrm{P}<0.05$ and Tukey multiple comparisons analysis. Each bar represents as a mean \pm SD of three independent experiments.
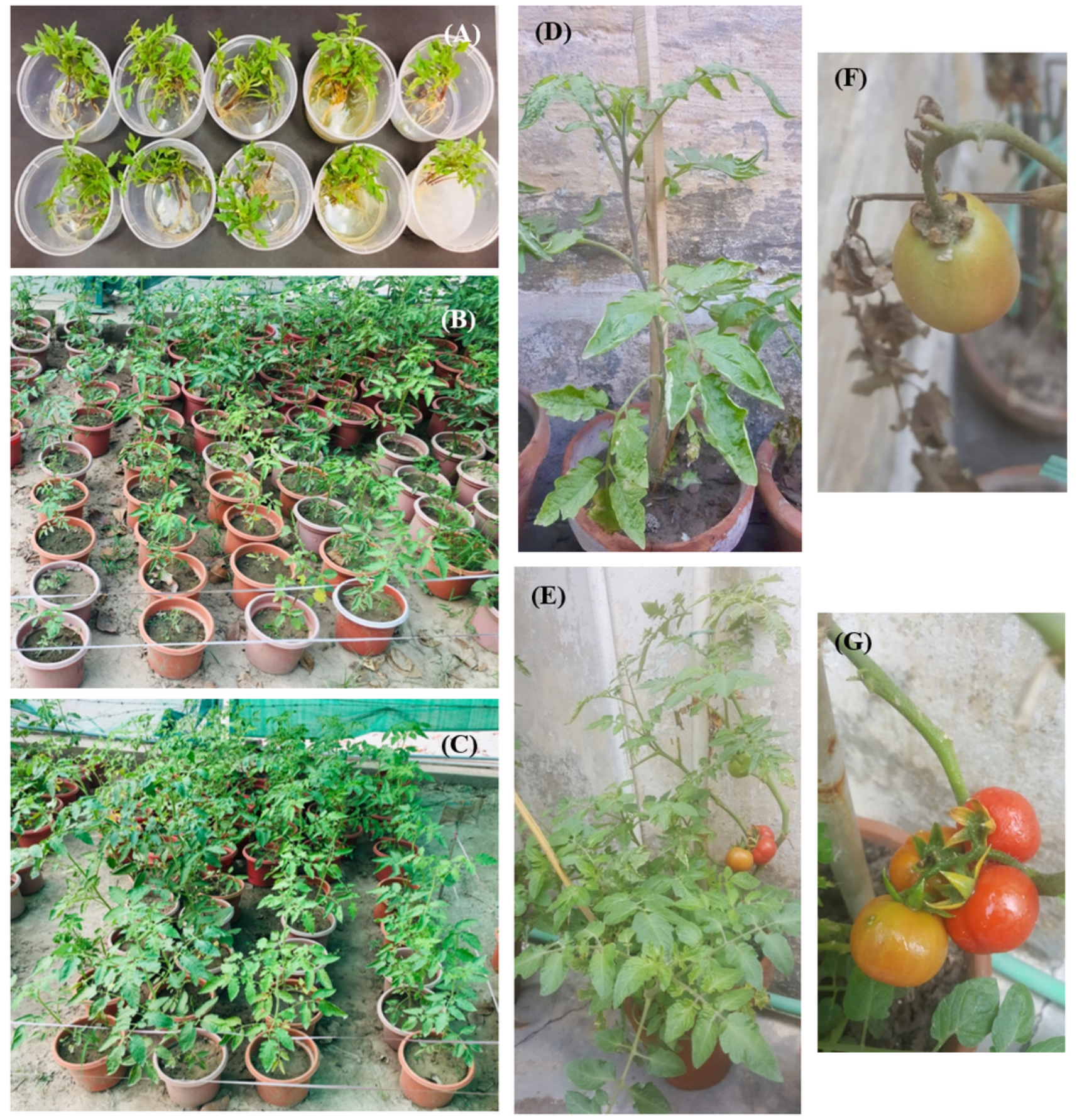

Figure 10 
Application of IONPs on infected tomato under greenhouse conditions. A: Showing root dipping protocoltomato seedlings treated with various concentrations of IONPs for two hours at room temperature, B \& C: Representative pictures of control and treated (nanoparticles concentrations) tomato plants under greenhouse conditions arranged with replicates, D: Representing control tomato plant (inoculated with F. oxysporum only), E: illustrating treated tomato plant with best concentration of IONPs $(12.5 \mu \mathrm{g} / \mathrm{mL}), \mathrm{F}$ \&G: Tomato fruits of control (upper) and treatment (lower) group.

A

Roots

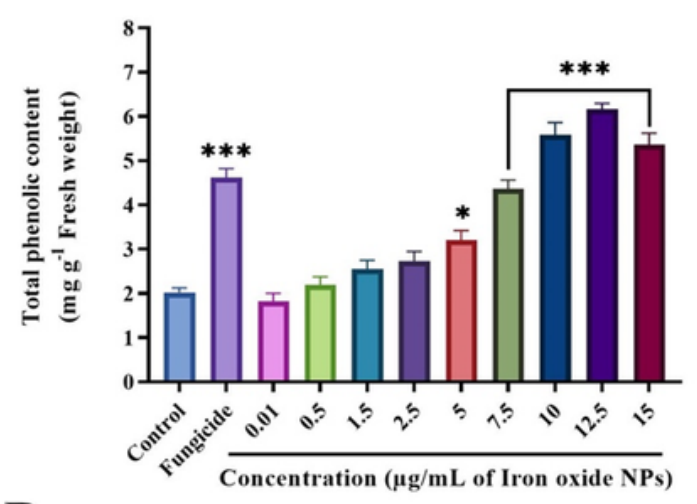

B

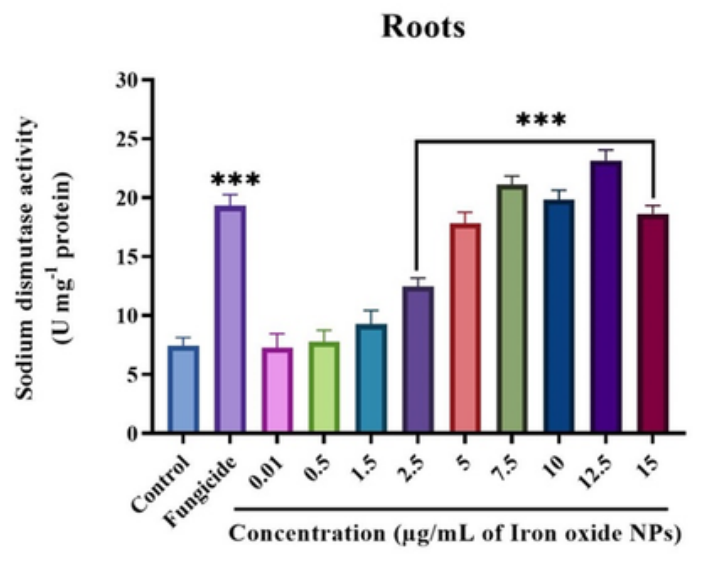

C

Roots

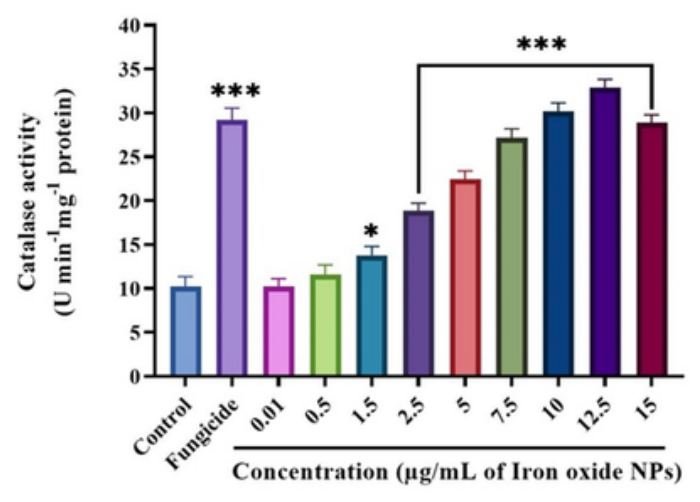

Shoots

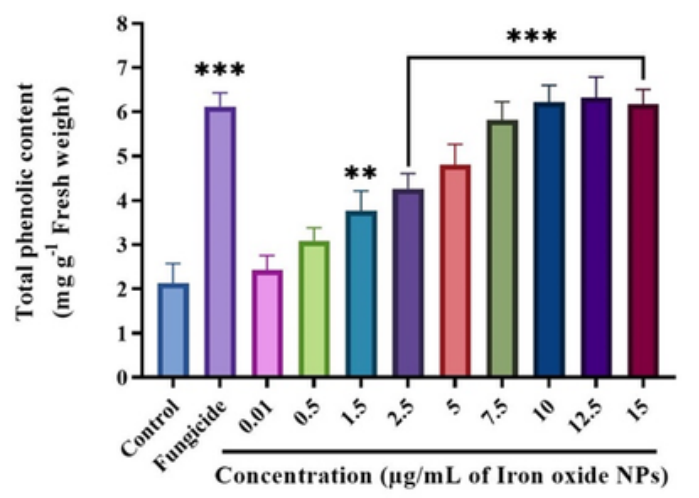

Shoots

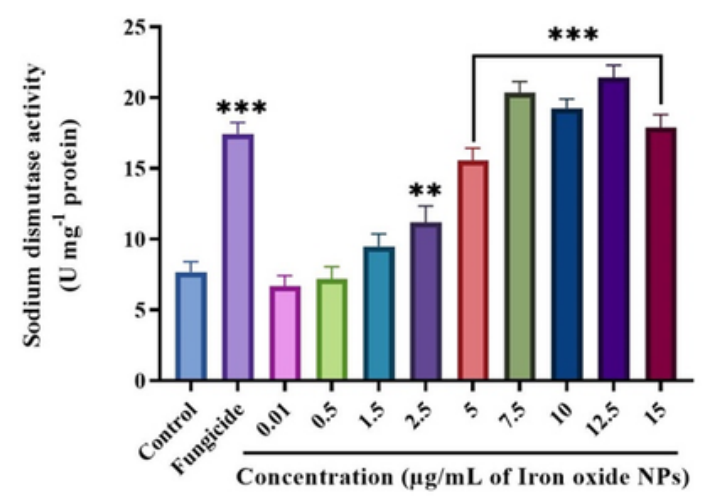

Shoots

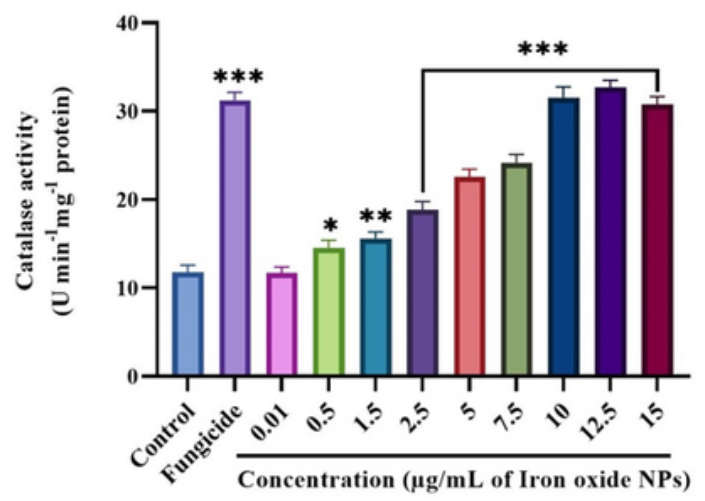

Figure 11 
Effect of various concentrations of IONPs on phenolic and antioxidant enzymes: Phenolic content (A), SOD (B) and CAT (C) in the roots and shoots of tomato plants infected with Fusarium oxysporum under pot condition. Significant-difference $\left({ }^{*} P<0.05 ; * \star P<0.01\right.$; $\left.* \star * P<0.001\right)$ among different concentrations of IONPs and control group performed by one-way-ANOVA at $\mathrm{P}<0.05$ and Tukey multiple comparisons analysis. Error bar represents as a mean \pm SD of three replicates.

A

Roots

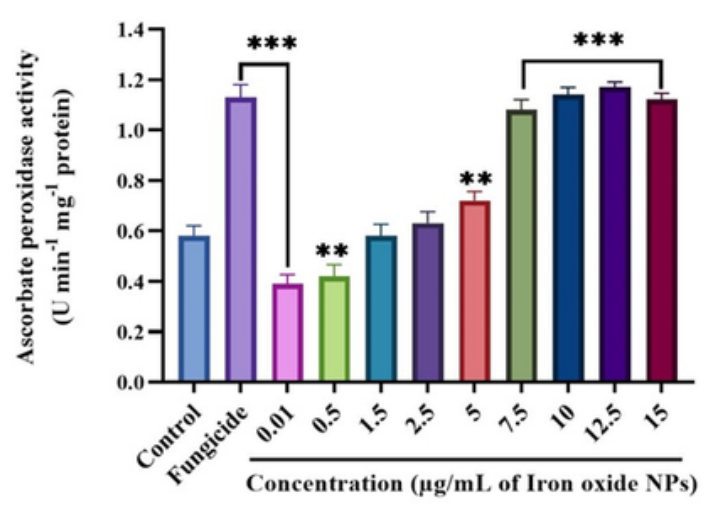

B

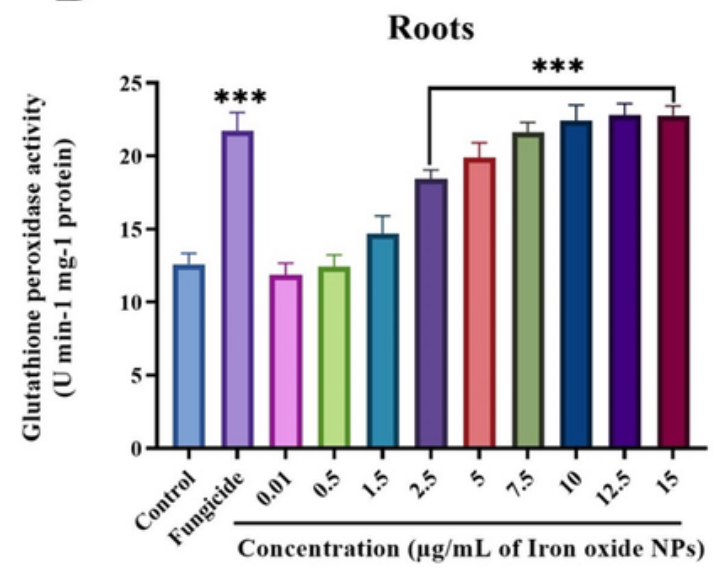

C

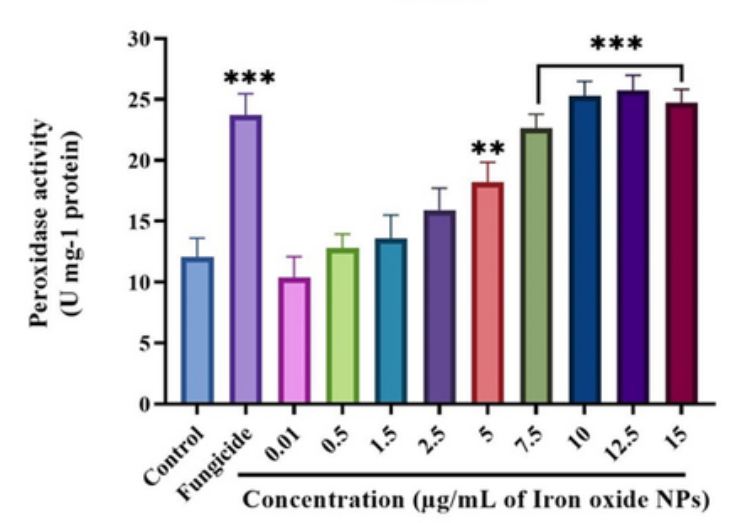

Shoots

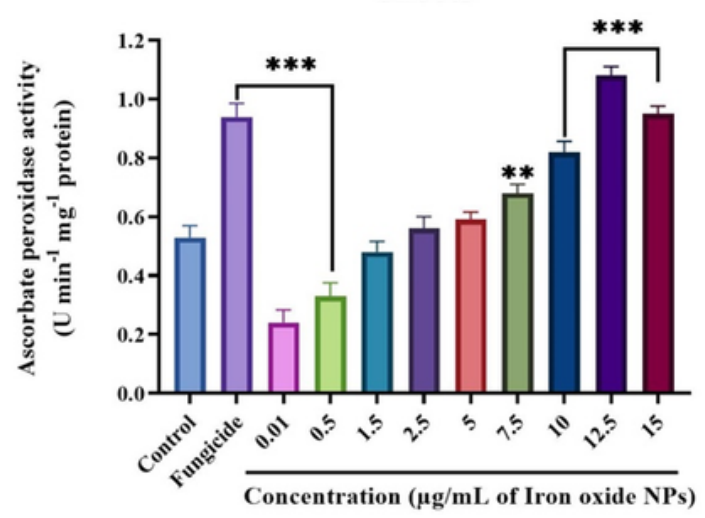

Shoots

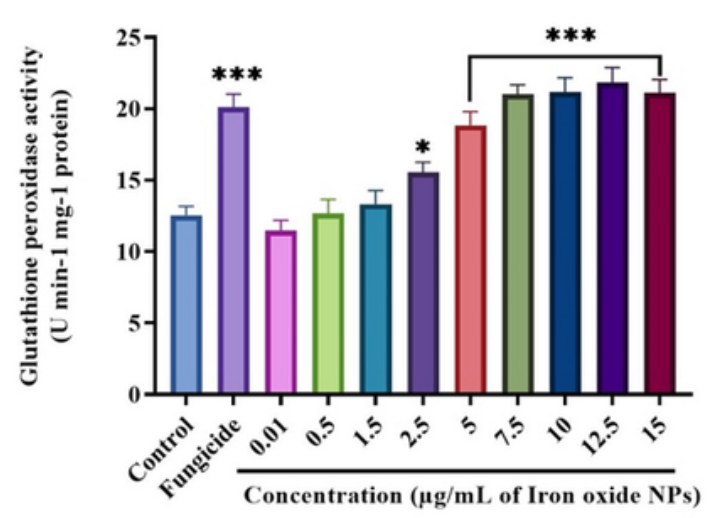

Shoots

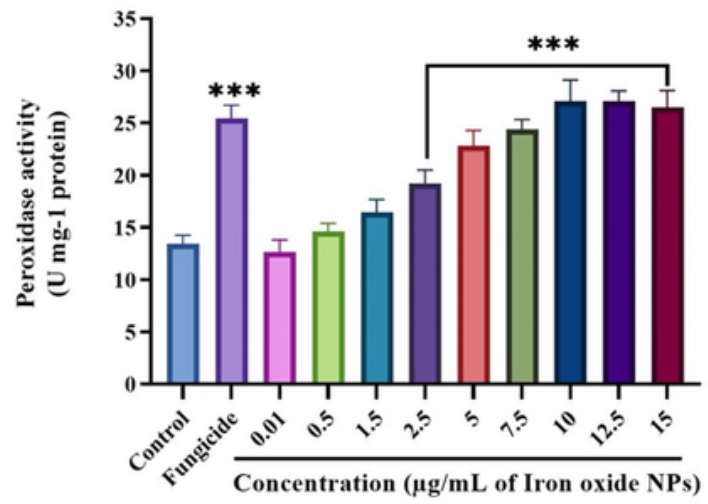

Figure 12 
Effect of various concentrations of IONPs on antioxidant defense enzymes: APX (A), GPX (B) and POD (C) in the roots and shoots of tomato plants infected with Fusarium oxysporum under pot condition.

Significant-difference ( $P<0.05$; $\left.{ }^{* *} P<0.01 ; * \star \star P<0.001\right)$ among different concentrations of IONPs and control group performed by one-way-ANOVA at $\mathrm{P}<0.05$ and Tukey multiple comparisons analysis. Error bar represents as a mean \pm SD of three replicates.

\section{Supplementary Files}

This is a list of supplementary files associated with this preprint. Click to download.

- GraphicalAbstract.png

- SupportingInformation.docx 